\title{
Zum Stand und zu den Perspek- tiven der allgemeinsprachlichen Lexikographie mit Deutsch und Slowenisch
}

\author{
Vida Jesenšek, Abteilung für Germanistik, Philosophische Fakultät, \\ Universität Maribor, Maribor, Slowenien (vida.jesensek@siol.net) \\ und \\ Herbert Ernst Wiegand, Germanistisches Seminar, Universität Heidelberg, \\ Heidelberg, Bundesrepublik Deutschland (herbert.ernst.wiegand@gs.uni- \\ heidelberg.de)
}

Zusammenfassung: Nach einer kurzen Übersicht über die allgemeinsprachlichen zweisprachigen Wörterbücher mit Deutsch und Slowenisch werden folgende Wörterbücher näher untersucht: Plet, DebN, DebS, PonsN und PonsS. Im ersten Teil der Wörterbuchanalyse werden der Benutzerbezug, die Wörterbuchbasis, die primär gebuchte Lexik sowie die Umtexte und eingelagerten Binnentexte berücksichtigt. Nur in Plet ist der Benutzerbezug relativ deutlich erkennbar. Bei den anderen Wörterbüchern bleibt er weitgehend undeutlich. In den vier neueren Wörterbüchern weisen alle betrachteten Komponenten erhebliche Mängel auf: z.B. fehlende mediostrukturelle Vernetzung von Umtexten und Wörterverzeichnis, fehlende Datenakzessivität bei den eingelagerten Binnentexten, ungeschickte Wahl der Wörterbuchbasis und unausgewogene Lemmaselektion. Im zweiten Teil der Wörterbuchanalyse werden anhand von Wörterbuchartikeln ausgewählte Aspekte des Wörterbuchgegenstands und der Wörterbuchform der genannten Wörterbücher untersucht; dabei werden die für das jeweilige Wörterbuch typischen Artikelmikrostrukturen dargestellt und Vorschläge gemacht, wie man die Artikelstrukturen verändern kann, damit die Gestaltung benutzerfreundlicher wird, und zwar auch dann, wenn das Datenangebot reichhaltiger ist. Dadurch werden einige Perspektiven für die Verbesserung der lexikographischen Versorgung im Sprachenpaar Deutsch und Slowenisch erkennbar.

Stichwörter: ANGABENADRESSIERUNG, BASALER WÖRTERBUCHARTIKEL, BENUTZERBEZUG, GLATTALPHABETISCHE HAUPTZUGRIFFSSTRUKTUR, HYBRIDE MIKROSTRUKTUR, KURZARTIKEL, MIKROARCHITEKTUR, MONOALPHABETISCHE MAKROSTRUKTUR, REINE MIKROSTRUKTUR, UMTEXT, ZWEISPRACHIGE LEXIKOGRAPHIE

\begin{abstract}
About the Position and Perspectives of General Lexicography with regard to German and Slovenian. A brief overview of general bilingual dictionaries with German and Slovenian is followed by a closer investigation of the following dictionaries: Plet, DebN, DebS, PonsN and PonsS. In the first part of the dictionary analysis the user reference, the dictionary basis, the primary recorded lexical items, as well as outer texts and phased-in inner texts are investigated. Only in Plet the user reference is relatively clearly recognisable. In the other
\end{abstract}


dictionaries it remains quite unclear. In all four more recent dictionaries all the components that have been investigated display serious shortcomings, e.g. lacking mediostructural linking of outer texts and central word list, the lack of data accessivity in the phased-in inner texts, inappropriate selection of the dictionary basis and the unbalanced lemma selection. In the second part of the dictionary analysis selected aspects of the dictionary subject matter and the dictionary form of the mentioned dictionaries are investigated by means of dictionary articles. In addition the typical article microstructures of each dictionary are given and proposals are made to change the article structures to produce a more user-friendly presentation, also when the data presentation is expanded. This reveals some perspectives for the improvement of the lexicographic treatment in the language pair German and Slovenian.

Keywords: BASIC DICTIONARY ARTICLE, BILINGUAL LEXICOGRAPHY, HYBRID MICROSTRUCTURE, ITEM ADDRESSING, MICROARCHITECTURE, MONOALPHABETIC MACROSTRUCTURE, OUTER TEXT, PURE MICROSTRUCTURE, SHORT ARTICLE, STRAIGHT ALPHABETICAL MAIN ACCESS STRUCTURE, USER REFERENCE

\section{Vorbemerkung}

Systemveränderungen und allgegenwärtige Forderungen nach mehr Zusammenarbeit und Integration im zusammenwachsenden Europa (EU) hatten in den letzten Jahren zur Folge, dass das Forschungs- und Arbeitsfeld der zweisprachigen Lexikographie an Interesse und Intensität gewonnen hat. Dazu trägt wesentlich auch die sprachpolitische Forderung nach Sprachenvielfalt und Mehrsprachigkeit in Europa bei. Das Bedürfnis nach zweisprachigen Lexika steigt mit dem wachsenden Interesse an dem Fremdsprachenlernen und mit immer intensiverer Übersetzungstätigkeit.

Durch die europäische politische Integration wurden einer Reihe von den in Europa gesprochenen Sprachen, und darunter auch dem Slowenischen, neue Positionen und Rollen zugeteilt. Das Slowenische ist immer öfter in der Position einer Fremd- oder Zweitsprache, die man erlernen will/soll und immer mehr die Ausgangs- oder Zielsprache der Übersetzung. Für beides sind qualitätsvolle und zuverlässige sprachliche Referenzwerke unentbehrlich. Da aber die gegenwärtige zweisprachige Lexikographie mit Slowenisch quantitativ eher bescheiden und qualitativ relativ mangelhaft ist, will der vorliegende Artikel zu einer besseren lexikographischen Praxis in der Erarbeitung der künftigen Sprachwörterbücher und zugleich zur Weiterentwicklung der metalexikographischen Forschung im slowenischen Sprachraum beitragen.

\section{Die Wörterbücher mit Deutsch und Slowenisch: eine Übersicht}

Ein Meilenstein in der Geschichte der slowenisch-deutschen zweisprachigen allgemeinen Lexikographie (die Anfänge reichen in das 16. Jh. zurück) war die Herausgabe des ersten slowenisch-deutschen Wörterbuchs größeren Umfangs 
von Maks Pleteršnik Ende des 19. Jhs. (Plet 1894-1895). Seitdem sind relativ viele allgemeine Wörterbücher unterschiedlichen Umfangs und verschiedener Komplexität erschienen. Im Cobiss, Slowenischen bibliographischen Informationssystem (http://www.cobiss.si/) kann man dies leicht überprüfen. In zwei chronologisch geordneten und hinsichtlich der Ausgangssprache differenzierten Listen (a) und (b) wird im Folgenden eine Auswahl präsentiert. Berücksichtigt wurden Wörterbücher mittleren und größeren Umfangs, nicht beachtet wurden dagegen kleinere Hand- und Schulwörterbücher.

(a) Zweisprachige Wörterbücher mit Slowenisch als Ausgangssprache

Pleteršnik, Maks (Hrsg.). 1894-1895. Transliterierte Ausg. 2006. Slovenskonemški slovar I-II [Slowenisch-deutsches Wörterbuch I-II]. Ljubljana: ZRC SAZU.

Kramarič, France (Hrsg.). 1905. Slovensko-nemški slovar [Slowenisch-deutsches Wörterbuch]. Wien/Leipzig: A. Hartleben.

Hubad, France (Hrsg.) 1908. Anton Janežičev slovensko-nemški slovar [Slowenisch-deutsches Wörterbuch von Anton Janežič]. Celovec/Klagenfurt: Tiskarna Družbe sv. Mohorja.

Bradač, Fran, Ivan Pregelj (Hrsg.). 1930. Slovensko-nemški slovar [Slowenisch-deutsches Wörterbuch]. Ljubljana: Jugoslovanska knjigarna.

Tomšič, France (Hrsg.). 1958, 1961, 1966, 1973, 1977, 1983, 1988, 1991, 1993. Slovensko-nemški slovar. Slowenisch-deutsches Wörterbuch. Ljubljana: Državna založba Slovenije.

Kotnik, Janko (Hrsg.). 1963, 1974, 1975, 1978, 1981, 1990, 1992, 1994. Langenscheidts Universal-Wörterbuch Slowenisch: Slowenisch-Deutsch, Deutsch-Slowenisch. Berlin usw.: Langenscheidt.

Gradišnik, Janez (Hrsg.). 1966, 1971, 1981, 1986, 1991/1992, 1998. Priročni slovensko-nemški slovar. Slowenisch-deutsches Handwörterbuch. Maribor: Obzorja.

Debenjak, Doris, Božidar Debenjak, Primož Debenjak (Hrsg.). 1995, 1997, 1999, 2003, 2008, 2009. Veliki slovensko-nemški slovar [Großes slowenisch-deutsches Wörterbuch]. Ljubljana: DZS. Print- und CD-ROMAusgaben.

PONS Splošni slovensko-nemški slovar. Kompaktwörterbuch SlowenischDeutsch. 2008. Ljubljana: Rokus Klett.

(b) Zweisprachige Wörterbücher mit Deutsch als Ausgangssprache

Kramarič, France (Hrsg.). 1907. Deutsch-slowenisches Wörterbuch. Wien, Leipzig: A. Hartleben.

Bartel, Anton (Hrsg.). 1905, 1921. Deutsch-slowenisches Hand-Wörterbuch. Von Anton Janežič. Klagenfurt, Prevalje: St. Hermagoras Bruderschaft.

Tominšek, Josip (Hrsg.). 1924. Nemško-slovenski slovar [Deutsch-slowenisches Wörterbuch]. Ljubljana: Ig. Kleinmayr \& Fed. Bamberg. 
Bradač, Fran, Janko Šlebinger (Hrsg.). 1928. Nemško-slovenski slovar [Deutschslowenisches Wörterbuch]. Ljubljana: Jugoslovanska knjigarna.

Tomšič, France (Hrsg.). 1938, 1944, 1954, 1974, 1959, 1980, 1985, 1986, 1989, 1990. Nemško-slovenski slovar. Deutsch-slowenisches Wörterbuch. Ljubljana: Državna založba Slovenije.

Gradišnik, Janez (Hrsg.). 1996, 1997, 2000, 2004, 2006, 2007. Nemškoslovenski, Slovensko-nemški slovar [Deutsch-slowenisches, Slowenischdeutsches Wörterbuch]. Maribor: Obzorja.

Debenjak, Doris, Božidar Debenjak, Primož Debenjak (Hrsg.). 1992, 1993, 1994, 1996, 1998, 1999, 2001, 2003, 2005, 2007, 2008. Veliki nemškoslovenski slovar. [Großes deutsch-slowenisches Wörterbuch]. Ljubljana: DZS. Print- und CD-ROM-Ausgaben.

Antič, Igor (Hrsg.) 1999, 2002. Nemško-slovenski slovar [Deutsch-slowenisches Wörterbuch]. Ljubljana: Mladinska knjiga.

PONS Splošni Nemško-slovenski slovar. Kompaktwörterbuch Deutsch-Slowenisch. 2006. Ljubljana: Rokus Klett.

Mit Rücksicht auf Umfang, Aktualität, Verbreitung aufgrund zahlreicher Neuauflagen und somit auch hinsichtlich der Relevanz und Repräsentativität für die zweisprachige Lexikographie mit Deutsch und Slowenisch bieten sich für eine detaillierte Betrachtung folgende Wörterbücher an:

Plet $=$ Slovensko-nemški slovar $[$ Slowenisch-Deutsches Wörterbuch $]$ von Pleteršnik.

DebN = Veliki nemško-slovenski slovar [Großes deutsch-slowenisches Wörterbuch] von Debenjak.

DebS = Veliki slovensko-nemški slovar [Großes slowenisch-deutsches Wörterbuch] von Debenjak.

PonsN = Splošni nemško-slovenski slovar [Allgemeines deutsch-slowenisches Wörterbuch] von PONS.

PonsS = Splošni slovensko-nemški slovar [Allgemeines slowenisch-deutsches Wörterbuch] von PONS.

Die Auswahl wird folgendermaßen begründet: Bei Plet handelt es sich um das erste umfangreiche Wörterbuch zu diesem Sprachenpaar, DebN und DebS sind die Wörterbücher mit dem umfangreichsten Lemmabestand, PonsN und PonsS gehören zu einer Wörterbuch-Serie der zweisprachigen Wörterbücher, die einen relativ großen Bekanntheitsgrad weltweit erreicht hat. Schließlich musste die Auswahl der zu betrachtenden Wörterbücher auch aus Platzgründen reduziert werden.

Im Verlauf der zwei weiteren Kapitel erfolgt eine zusammenfassende Darstellung der ausgewählten Wörterbücher. Sie werden in folgenden Hinsichten charakterisiert: Benutzerbezug, Wörterbuchbasis, primär gebuchte Lexik, Umtexte, Wörterbuchgegenstand und Wörterbuchform. 
3. Wörterbuchanalyse I: Benutzerbezug, Wörterbuchbasis, primär gebuchte Lexik, Umtexte und eingelagerte Binnentexte

In diesem Kapitel wird dargestellt, wie die ausgewählten Wörterbücher sich auf ihre Adressaten beziehen, ihre Benutzerbedürfnisse berücksichtigen und welche Funktionen sie damit erfüllen möchten. Betrachtet werden die Wörterbuchbasis, der Lemmabestand hinsichtlich der Selektion und des Umfangs sowie entsprechende Aussagen in den Umtexten. Die Darstellungen in diesem Kapitel haben zum Ziel, Aussagen über die Benutzerangemessenheit in Bezug auf ihre funktionalen Aspekte zu formulieren und somit Grundlagen für die nachfolgende Analyse zum Wörterbuchgegenstand und zur Wörterbuchform (Kap. 4) zu schaffen.

\subsection{Plet}

Das slowenisch-deutsche Wörterbuch von Pleteršnik entstand aufgrund der gesellschaftlichen Notwendigkeiten und Wünschen, die im slowenischen Sprachraum um die Mitte des 19. Jhs. festgestellt und geäußert wurden und im Einklang mit den sprachorientierten nationalen Forderungen der europäischen revolutionären Zeit um das Jahr 1848 standen. Das Wörterbuchprogramm entstammt nämlich den Tätigkeitsplänen des 1848 gegründeten Slowenischen Vereins (Slovensko društvo), dessen primäre bildungskulturelle Aufgabe die Erarbeitung und Herausgabe eines repräsentativen Wörterbuchs des Slowenischen gewesen war. Ein solches Wörterbuch sollte in zwei Teilen, einem deutschslowenischen und einem slowenisch-deutschen Teil erscheinen. Während der deutsch-slowenische Teil in der Tat relativ schnell erarbeitet und herausgegeben wurde (1860), dauerte es trotz der landespolitischen finanziellen und personellen Unterstützung bis zum Jahr 1894 bzw. 1895, bis die beiden Bände des slowenisch-deutschen Teiles unter der Redaktion von Pleteršnik erschienen sind.

Plet ist ein zweibändiges allgemeines zweisprachiges Wörterbuch und enthält genau 102522 Lemmata der slowenischen Ausgangssprache (Furlan 2006: IX). Über den Wörterbuchplan und die Wörterbuchkonzeption von Plet ist inzwischen an mehreren Stellen ausführlich geschrieben worden (u.a. Jakopin 1994 und 1997, Jesenšek 2004, Furlan 2008); aus Platzgründen werden an dieser Stelle nur die für die nachfolgenden Ausführungen wesentlichen Informationen darüber gegeben. Das sprachliche Ausgangsmaterial gründete auf einem systematisch durchdachten Wörterbuchkonzept und entstammte zahlreichen und relativ vielfältigen Quellen, die im Vorspann (Abkürzungsverzeichnis) akribisch verzeichnet sind. $\mathrm{Zu}$ den primären Textquellen zählten vorrangig theologisch-kirchliche und profane Literatur sowie publizistische und fachliche Texte, die vom Anfang des slowenischen Schriftentums im 16. Jh. bis zu der 2. Hälfte des 19. Jhs. veröffentlicht wurden. Anhand des Abkürzungsverzeichnisses sind ebenso sekundäre, tertiäre und weitere Quellen der Wörter- 
buchbasis identifizierbar. Bei der Materialerhebung und -übernahme wurden die bedeutendsten Wörterbücher jener Zeit systematisch konsultiert (vor allem ältere (auch handschriftliche) zweisprachige Wörterbücher mit Slowenisch und Deutsch, aber auch einsprachige Wörterbücher des Russischen, KroatischSerbischen, Deutschen (Grimm) und dialektale (bayrische, italienische) Wörterbücher. Die Letzteren wurden insofern konsultiert, als zwischensprachliche lexikalische Zusammenhänge gesucht wurden. Unter den tertiären Quellen wurden vorhandene slowenische Grammatiken und sprachwissenschaftliche Abhandlungen (vor allem zur Phonetik, Dialektologie und Terminologie) weitgehend berücksichtigt. Die Wörterbuchbasis wurde weiterhin durch mehr oder weniger umfangreiche Wortsammlungen der gebildeten Muttersprachler sowie der dialektsprechenden Informanten erweitert.

Gemäß der Wörterbuchkonzeption, wie sie in dem relativ umfangreichen Einleitungstext in das Wörterbuch von Pleteršnik selbst beschrieben wurde, bestand der Hauptzweck des Wörterbuchs darin, als repräsentatives Wörterbuch des Slowenischen gelten zu können. Die gebuchte Lexik sollte die gedankliche Welt der Slowenen, den Geist der Sprache und der Nation im möglichst vollen Umfang darstellen (Pleteršnik 2006: VII). Das Ziel der Lexikographen bestand also darin, eine Art Inventarisierung der slowenischen Lexik durchzuführen und somit ein historisches Wörterbuch des Slowenischen zu erstellen. Aus finanziellen und vor allem aus personellen Gründen erwies sich die Einbeziehung der historischen Dimension jedoch bereits in der Planungsphase als wenig realistisch, so dass man sich entschloss, mit dem Wörterbuch eher "praktische Zwecke“" zu verfolgen. Diese bestanden vor allem in der (möglichst ausführlichen) Dokumentation der slowenischen usuellen standardsprachlichen und dialektalen Lexik. Es wurde eine möglichst hoher Vollständigkeitsgrad bei der äußeren Selektion angestrebt, so dass nicht nur die schriftlich belegte allgemeinsprachliche Lexik im Wörterbuch enthalten ist, sondern in relativ hohem Maße ebenso der dialektale und fachliche Wortschatz sowie eine beträchtliche Anzahl der Lexik aus älteren Perioden des slowenischen Schriftentums seit dem 16. Jh. Die regional, dialektal oder fachsprachenspezifisch verbreitete Lexik ist im Plet weitgehend diatopisch und diatechnisch markiert. Von der Buchung ausgeschlossen blieben lediglich die gelegentlich gebildete bzw. nicht usuelle Lexik sowie Fremdwörter, insofern slowenische Äquivalente belegt worden waren. Die potentiellen Benutzer sind somit primär Slowenischsprechende, die sich über die muttersprachliche Lexik ausführlich informieren wollen.

Nach der Betrachtung der Wörterbuchbasis, des Umfangs der gebuchten Lexik und ihrer Selektion sowie aufgrund der Aussagen zu den geplanten Benutzern in den Umtexten kann festgestellt werden, dass die Konzipierung und Ausarbeitung von Plet in hohem Maße auf den spezifischen gesellschaftlichen und nationalorientierten Forderungen in der Mitte des 19. Jhs. basierte. Diese bestanden darin, eine ganzheitliche lexikographische Darstellung der slowenischen usuellen Lexik in ihrer allgemeinsprachlichen (schriftsprachli- 
chen und regional-dialektalen) sowie fachsprachlichen und historischen Ausprägung zu erarbeiten. In Bezug auf den primären muttersprachlichen Wörterbuchbenutzer lässt sich Plet als hochgradig benutzeradäquat charakterisieren. Es ist bisher noch immer das umfangreichste deutsch-slowenische Wörterbuch mit slowenischer Ausgangssprache und bleibt auch nach dem Erscheinen des großen fünfbändigen einsprachigen Wörterbuchs des Slowenischen (Slovar slovenskega knjižnega jezika 1980-1991, 93142 Lemmata) eine wichtige thesaurische Sammlung der slowenischen Lexik, die die gesamte Lexikographie mit Slowenisch im 20. Jh. beeinflusst hat (Toporišič 1998: 5). Die Wahl des Wörterbuchtyps (zweisprachiges Wörterbuch mit Slowenisch als Ausgangs- und Deutsch als Zielsprache) ist wohl gesellschaftspolitisch begründet und ist vor allem in Abhängigkeit mit der damaligen Zugehörigkeit des slowenischen Sprachraumes zur Österreichischen Monarchie zu betrachten. Da bei ca. 10 \% der aufgenommenen Lexik jedoch Slowenisch (und nicht Deutsch) als Sprache der semantischen Kommentare vorkommt (Furlan 2006: IX), lassen sich beim zweisprachigen Plet zugleich Ansätze eines einsprachigen slowenischen Bedeutungswörterbuchs erkennen. Dies mag seine oben besprochene Funktionalität zusätzlich rechtfertigen.

\subsection{PonsN und PonsS}

Die neuesten Wörterbücher mit Deutsch und Slowenisch sind Lizenzausgaben der Pons-Wörterbücher des Klett-Verlages. Das PonsN und PonsS sollen jeweils ca. 70000 "Stichwörter, Phrasen und Satzbeispiele“ umfassen, so laut Angaben auf dem Umschlag, in der Einleitung und in Werbetexten. Nach einer genaueren Untersuchung verzeichnen PonsN und PonsS allerdings weniger Lemmata als angedeutet, nämlich ca. 41000 bzw. 35 000. Die Einschätzung gründet auf folgender Überprüfung: Im jeweiligen Wörterbuch wurden Lemmata auf 12 zufällig ausgewählten Seiten gezählt. Ihre Durchschnittsanzahl pro Seite (47, 5 im PonsN und 41 im PonsS) und die Einbeziehung des Gesamtumfangs des Wörterverzeichnisses (das Wörterverzeichnis im PonsN umfasst 874 und im PonsS 856 Seiten) ergeben die genannte Anzahl der aufgenommenen Lemmata, die als realistischer Schätzwert gelten kann.

Die Lemmaliste im PonsN basiert auf der deutschen Lemmaliste des KlettVerlages. Das Wörterbuch solle den aktuellsten deutschen Wortschatz verzeichnen (samt Anglizismen und Neologismen), ebenso eine Auswahl an österreichischer und Schweizer Lexik sowie eine (unbestimmte) Anzahl der Fachwörter und stilistisch markierter Lexik. Laut Aussagen in der Einleitung (PonsN 2006: V) ist die Auswahl der Lexik in der Zusammenarbeit mit "vielen Übersetzern und Germanisten" auf den slowenischen Benutzer zugeschnitten worden, es bleibt jedoch völlig unklar, was gemeint ist.

Auch das PonsS will höchstaktuell sein, es soll „die aktuellste Lexik des gegenwärtigen Slowenisch" verzeichnen (PonsS 2008: V). Die Lemmaliste der slowenischen Ausgangssprache wurde laut Einleitung in mehreren Selektions- 
schritten gewonnen. Die Wörterbuchbasis bildete das slowenische Textkorpus Nova beseda (http://bos.zrc-sazu.si/s_beseda.html), ein frei zugängliches Akademiekorpus. Dieses enthält gegenwärtig (Januar 2009) 240 Millionen Wörter, wobei einen weit überwiegenden Anteil des Korpus publizistische Texte darstellen. Im Vergleich mit dem ebenso seit 2006 frei zugänglichen slowenischen Korpus FidaPLUS (www.fidaplus.net) im gegenwärtigen Umfang von 621 Millionen Wörtern gilt Nova beseda als bedeutend weniger repräsentativ für den gegenwärtigen slowenischen Sprachgebrauch, was natürlich die Frage aufwirft, warum die Selektion "der aktuellsten slowenischen Lexik" gerade anhand dieses Korpus erfolgte. Einzelne Selektionskriterien werden allerdings nicht erläutert, so dass man nicht weiß, wie die Aktualität der gegenwärtigen slowenischen Lexik gemessen und was darunter überhaupt verstanden wurde. Die Fachlexik sollte in den beiden Wörterbüchern reichlich vertreten sein, zumal im jeweiligen Abkürzungsverzeichnis Abkürzungen zur diatechnischen Markierung von 52 verschiedenen Sachgebieten verzeichnet sind. Allerdings lässt sich aus den Aussagen in den Umtexten beider Wörterbücher Näheres über die Auswahl und Anzahl der Fachlexik nicht nachvollziehen.

Über den Benutzerbezug erfährt man in der Einleitung zum PonsN, dass es "für möglichst breiteste Benutzerkreise" vom Nutzen sein will. Angesprochen ist sowohl der slowenisch sprechende Benutzer, "der mit der deutschen Sprache in Kontakt kommt" als auch der deutschsprachige Benutzer, der "Slowenisch lernt" (PonsN 2006: V). Zumal die knappe Beschreibung der Benutzerzielgruppen in der Einleitung vom PonsS mit der entsprechenden Passage im PonsN völlig identisch ist, ist anzunehmen, dass bei der Erarbeitung beider Wörterbücher die verschiedenen Ausgangsprachen und folglich spezifische Benutzerbedürfnisse, Benutzungsanlässe und -situationen falls überhaupt, eher wenig, eine Rolle gespielt haben. So rechnen beide Wörterbücher mit folgenden Benutzungssituationen: (1) die Benutzung in konfliktbedingten rezeptiven und produktiven (vor allem translatorischen) Situationen, in denen sich, nach den Wörterbüchern, vorrangig ein slowenisch sprechender Benutzer befindet, wenn er in Kontakt mit der deutschen Sprache kommt und (2) die Benutzung in rezeptiv- und produktiv ausgerichteten Lernsituationen, in denen sich allerdings nicht nur ein deutschsprachiger Slowenisch-Lerner befindet, wie die Wörterbücher suggerieren, sondern ebenso ein slowenischsprachiger DeutschLerner.

Zum Benutzerbezug der beiden Pons-Wörterbücher ist Folgendes festzustellen: Die Auswahl und der Umfang der gebuchten Lexik richten sich vorrangig nach dem anvisierten Lerner-Benutzer. Dafür sprechen das Streben nach der Aktualität der aufgenommenen Lexik, die Textkorpora als Wörterbuchbasis und ebenso Umtexte im Nachspann beider Wörterbücher. Im PonsN findet man eine relativ umfangreiche (28 Seiten) auf Slowenisch verfasste Wörterbuchgrammatik des Deutschen, im PonsS dagegen eine vergleichbare auf Deutsch verfasste Wörterbuchgrammatik des Slowenischen. Bei den Flexionstabellen in den beiden Grammatiken fällt auf, dass sie in keiner direkten Verbindung mit dem Wörterbuchtext stehen, was u.a. mit einer entsprechenden 
Nummerierung der Flexionsklassen möglich gewesen wäre. Die übrigen Umtexte im Nachspann beider Wörterbücher (Liste der Zahlwörter, Maße und Gewichte, Listen geographischer Namen in deutsch- und slowenischsprachigen Gebieten, Nützliche Redewendungen (i.e. Kommunikationsphrasen), Musterbriefe) sind inhaltlich identisch und parallel zweisprachig; verschiedene Sprachen nehmen allerdings jeweils eine unterschiedliche Ausgangsposition ein. Darüber hinaus enthalten beide Wörterbücher eine kleinere Anzahl von eingelagerten Binnentexten (Land und Leute), in denen kulturelle, nationale und/oder sprachliche Spezifika erläutert werden. Ihr Nachteil besteht allerdings darin, dass der Benutzer weder über die alphabetische Hauptzugriffsstruktur noch über eine andere äußere Zugriffsstruktur (wie z.B. über eine Registerzugriffsstruktur) auf sie zugreifen kann und so der Eindruck entsteht, dass sie eher beliebig in den beiden Wörterbüchern verstreut sind.

\subsection{DebN und DebS}

Nach Angaben im Vorwort verzeichnet das DebN ca. 120500 und mit sog. Dubletten ca. 123000 „Lemmata des Gegenwartsdeutsch“ (DebN 2001: V) und das DebS ca. 100000 „Lemmata der gegenwärtigen slowenischen Standardsprache“. Bei der Auswahl der Lexik wurde „eine besondere Aufmerksamkeit der Sprache der täglichen allgemeinen Kommunikation sowie der Fachsprache geschenkt" (DebS 2003: V), während bei der Materialerhebung die Lexik der Literatur weniger berücksichtigt und dialektale und umgangssprachliche Ausdrücke prinzipiell gemieden wurden. Dasselbe gilt auch für das DebN, zumal die Aussagen im Vorwort inhaltlich fast identisch sind. Prinzipen, nach denen die Auswahl der aufzunehmenden Lexik erfolgte, lassen sich aus den Umtexten beider Wörterbücher jedoch nicht genauer nachvollziehen.

Aus dem Quellenhinweis im DebS geht hervor, dass unter den primären Quellen deutschsprachige (!) Fachtexte (vorrangig zur Botanik und Zoologie) und ihre slowenischen Übersetzungen dominieren. Unter den sekundären Quellen haben neben den allgemeinen einsprachigen und zweisprachigen slowenisch-deutschen Wörterbüchern einen sehr großen Anteil wiederum deutsche Fachlexika und enzyklopädische Referenzwerke. Dementsprechend sind fachsprachliche Ausdrücke im DebS zahlenmäßig überproportional stark vertreten. Das Abkürzungsverzeichnis notiert 22 Abkürzungen zur diatechnischen Markierung der Fachlexik. Tertiäre Quellen vermisst man in der Wörterbuchbasis vom DebS. Über die Wörterbuchbasis von DebN ist Ähnliches zu berichten, da das Literaturverzeichnis dem aus dem DebS im Wesentlichen gleicht (vgl. Jesenšek 2005).

Die Dominanz der deutschsprachigen Wörterbuchbasis mag verwundern; sie kommt aber offensichtlich durch die starke Ausrichtung der beiden Wörterbücher auf die Bedürfnisse bei der Übersetzung zustande. Denn auf die Translationssituationen, die zur Wörterbuchbenutzung führen können und auf die Probleme der Äquivalentfindung wird in den einleitenden Umtexten mehrere Male hingewiesen, während die Wörterbuchbenutzung bei der gestörten 
Textrezeption und Textproduktion sowie die in Lernsituationen nicht thematisiert wird. Mit der Ausnahme einer kurzen slowenischen Wörterbuchgrammatik im DebS enthalten DebN und DebS keine weiteren Umtexte. - Zusammenfassend ist anzumerken, dass die Benutzerbezüge in DebN und DebS nur schwer nachvollziehbar sind.

\section{Wörterbuchanalyse II: Wörterbuchgegenstand und Wörterbuchform}

In diesem Kapitel werden Teile des Wörterbuchgegenstandes und Ausschnitte der Wörterbuchform der ausgewählten Wörterbücher betrachtet. Der Wörterbuchgegenstand eines bestimmten Sprachwörterbuchs ist die Menge der in diesem Wörterbuch lexikographisch bearbeiteten Eigenschaftsausprägungen von wenigstens einer, höchstens aber von endlichen vielen sprachlichen Eigenschaften bei einer bestimmten Menge von im Wörterbuch lemmatisch und nichtlemmatisch genannten sprachlichen Ausdrücken, die zu mindestens einem Wörterbuchgegenstandsbereich gehören (vgl. Wiegand 1998: 301f). Zu zweisprachigen Wörterbüchern gehören zwei Wörterbuchgegenstandsbereiche: Im vorliegenden Fall sind dies das Deutsche und sein korrekter Gebrauch sowie das Slowenische und sein korrekter Gebrauch. Bei unseren Bemerkungen zum Wörterbuchgegenstand beschränken wir uns auf Wörter der drei Hauptwortarten Substantiv, Verb und Adjektiv sowie auf Mehrwortbenennungen. Der Schwerpunkt der nachfolgenden Wörterbuchanalyse liegt auf der Wörterbuchform; dennoch kann (aus Platzgründen) nur ein relativ schmaler Ausschnitt aus der Wörterbuchform der ausgewählten Wörterbücher Berücksichtigung finden: Betrachtet werden vor allem reine und hybride Artikelmikrostrukturen; ein kurzer Blick wird auch auf artikelinterne Angabeadressierungsstrukturen, auf die alphabetischen Hauptzugriffsstrukturen sowie die monoalphabetischen Makrostrukturen geworfen. Bei der Wörterbuchanalyse wird vor allem auf Wiegands Theorie der Wörterbuchform zurückgegriffen (vgl. u.a. Hausmann und Wiegand 1989, Kammerer und Wiegand 1998/99; Konerding und Wiegand 1994; Meyer und Wiegand 2000; Pan Zaiping und Wiegand 1995; Schierholz und Wiegand 2005; Wiegand 1989, 1989a, 1989b, 1990, 1990a, 1991, 1994/95, 1995, 1995a, 1996, 1996a, 1996b, 1997, 1998, 1998a, 1998b, 1999, 1999a, 2000, 2000a, 2000b, 2000c, 2000d, 2001, 2001a, 2002, 2002a, 2002b, 2002c, 2002d, 2003, 2003a, 2004, 2005, 2005a, 2005b, 2005c, 2005d, 2006, 2006a, 2006b, 2007 2007a, 2007b, 2007c, 2007d, 2007e, 2008, 2008a, 2009, 2009a). Das Ziel der nachfolgenden Wörterbuchanalyse besteht vor allem darin, die wichtigsten der für die ausgewählten Wörterbücher charakteristischen Typen von textuellen Strukturen darzustellen sowie Ausschnitte aus dem Wörterbuchgegenstand und damit das Datenangebot kritisch zu beleuchten.

\subsection{Plet}

Gegeben seien die Wörterbuchartikel in Abb. 1. 
wa 1

glęšstati, -am, vb. impf. 1) warten, pflegen, $C$., $M$.; živino g, Kr.-Erj. (Torb.); g. se, sich wohl sein lassen, Jan.; prim. glajštati; - 2) vermögen, haben, Mur., Jan.; ne gleštam krajcarja, Št.; pri tej hiši dober kruh gleštajo, Gor.

\section{wa2:}

óče, -ę́ta, $m$. der Vater; stari o., der Großvater; duhovni o., der geistliche Vater (eines primicierenden Priesters), Št.; krušni o., der Pflegevater; cerkveni očetje, die Kirchenväter, Cig., Jan., $n k$.; veliki o. = starejšina, $C$.; krstni o. = boter, ogr. $-C$.

$\mathrm{wa}_{3}-\mathrm{wa}_{19}$

bakrár, -rja, $m$. der Kupferschmied, $Z$

bakrârnica, ${ }^{\star} f$. die Kupferschmiede, $Z$.

bakrârstvo, $n$. das Kupferschmiedgewerbe, $Z$.

bákrast, adj. kupferartig, kupferfärbig, $Z$.

bakrện, adj. kupfern, Kupfer-, Mur., Cig., Jan., Cig. (T.), $n k$.; bakrena ruda, das Kupfererz, Cig. (T.).

bakrệnast, adj. kupfericht, Cig., Jan.

bakrênnəc, -nca, $m$. die Kupferlasur, Z.; modri b. Erj. (Min.); rdeči b., das Rothkupfererz, Erj. (Min.).

bakreníca, $f$. das Cementwasser (eine kupferhältige

Flüssigkeit), Cig., Erj. (Min.); das Kupferwasser, Jes.

bakreník, $m$. das Kupferbergwerk, $Z$.

bakrenína, $f$. die Kupferwaare, $Z$.

bákrenje, $n$. die Verkupferung, $Z$.

bákriti, -im, $v b$. impf. verkupfern, $Z$.

bakrorę̂stvọ, $n$. die Kupferstecherei, (-štvo, Cig.)

bakrorẹ̀z, -rẹ́za, $m$. der Kupferstich, Cig., Jan., $n k$.

bakrorệzəc, -zca, $m$. der Kupferstecher, Cig., Jan. $n k$.

bakrorẹ́zən, -zna, adj. Kupferstech-: bakrorezna šola, Navr. (Let.).

bakrorệzje, $n$. = bakrorestvo, Jan wa $20-w_{33}$

glinît, adj. thonhältig, Cig. (T.).

glíniti, -im, $v b$. impf. mit Thon überziehen, Cig

1. glínja, f., Mur., Cig., Jan., pogl. glina.

2. glinja, $f$. die grüne Nussschale, $C$.; - prim. klenovec, klinovina.

glínjavica, $f .=2$. glinja, $C$.

glínjavka, $f$. = glinjavica, Fr.-C.

glînje, $n$. der Thon, Cig., Nov. -C.

glínjevica, $f$. Cig., Jan., pogl glinovica.

glînka, $f$. = glinica, $Z$., $C$.

glinokòp, -kópa, $m$. der Thongräber, $C i g$.

1. glínov, adj. iz gline, Trub.-C.

2. glinov, adj. glinova ovca, Nov., pogl. glenav.

glinovàt, -áta, adj. thonhältig, $Z$; glinovati železovec, Cig. (T.); pogl. glinovnat.

glínovəc, -vca, $m$. der Thonstein, Cig., Jan.; - prim. glinavec.

wa $34-w a_{35}$

sočûtje, $n$. das Mitgefühl, die Sympathie, Cig., Jan., C., $n k$.

sočûvstvən, -stvəna, adj. sympathetisch, $C$.; sočuvstveni živec, Cig. (T.).

wa $36-$ wa 37

glísta, $f$. 1) gliste, die Eingeweidewürmer (entozoa, helminthes): navadna g., der Spulwurm (ascaris lumbricoides), otročja g., der Kinderwurm, die Kindermade (oxyuris vermicularis), Erj. (Ž.); konjska g., der Palissadenwurm (strongilus), ovčja g., der Schafwurm (strongilus filaria), svinjska g., der Kratzer (echinorynchus gigas), ribja g., der Inger (myxine), Erj. (Z.); - der Regenwurm, Cig. C., jvzhŠt.; - 2) glíste, = glisti, SlGradec-C., Notr., Levst. (Rok.).

glístast, adj. 1) wurmförmig, Mur., V.-Cig., Jan.; - 2) = glistav, Mur.

Abb. 1: Wörterbuchartikel wa bis $_{1} \mathrm{wa}_{37}$ aus Plet

Im Folgenden betrachten wir zunächst hierarchische reine Artikelmikrostrukturen von Kurzartikeln aus Plet in abstrakter und konkreter Ausprägung. Textuelle Strukturen dieses Typs sind die wichtigsten Teilstrukturen von hierarchischen (abstrakten und isomorphen konkreten) reinen Artikelkonstituentenstrukturen. Bei der Bildung der Letztgenannten werden die nichttypographischen Mikrostrukturanzeiger (wie z.B. Kommata, Punkte, Strichpunkte und senkrechte Striche als Textkonstituenten berücksichtigt (vgl. z.B. Wiegand 2000a: 235ff)). Dagegen ist dies bei der Konstruktion von hierarchischen Artikelmikrostrukturen nicht der Fall. Alle Artikel in Abb. 1 sind vollständig kondensierte Wörterbuchartikel (i.S.v. Wiegand 2003a: 205ff); dies bedeutet, 
dass sie keine Angabetexte aufweisen. Der Standardisierungsgrad der Artikel ist relativ hoch: Bei gleichem Lemmazeichentyp sind die Artikel in Plet häufig gleichartig gestaltet, so dass auch die lexikographische Bearbeitung der jeweiligen artikelspezifischen Ausschnitte des Wörterbuchgegenstandes relativ einheitlich ist; daher sind die konkreten hierarchischen Artikelmikrostrukturen der Wörterbuchartikel häufig isomorph. Dies gilt vor allem für Kurzartikel, von denen viele Einzeilenartikel sind, wie z.B. $\mathrm{wa}_{3}-\mathrm{wa}_{6}$ in Abb. 1. Beispielsweise sind die konkreten hierarchischen reinen Artikelmikrostrukturen von wa $\mathrm{w}_{11}-\mathrm{wa}_{13}$ isomorph, und die drei konkreten Mikrostrukturen der Artikel sind zur zugehörigen abstrakten hierarchischen Mikrostruktur isomorph. Dies ist in Abb. 2 dargestellt.

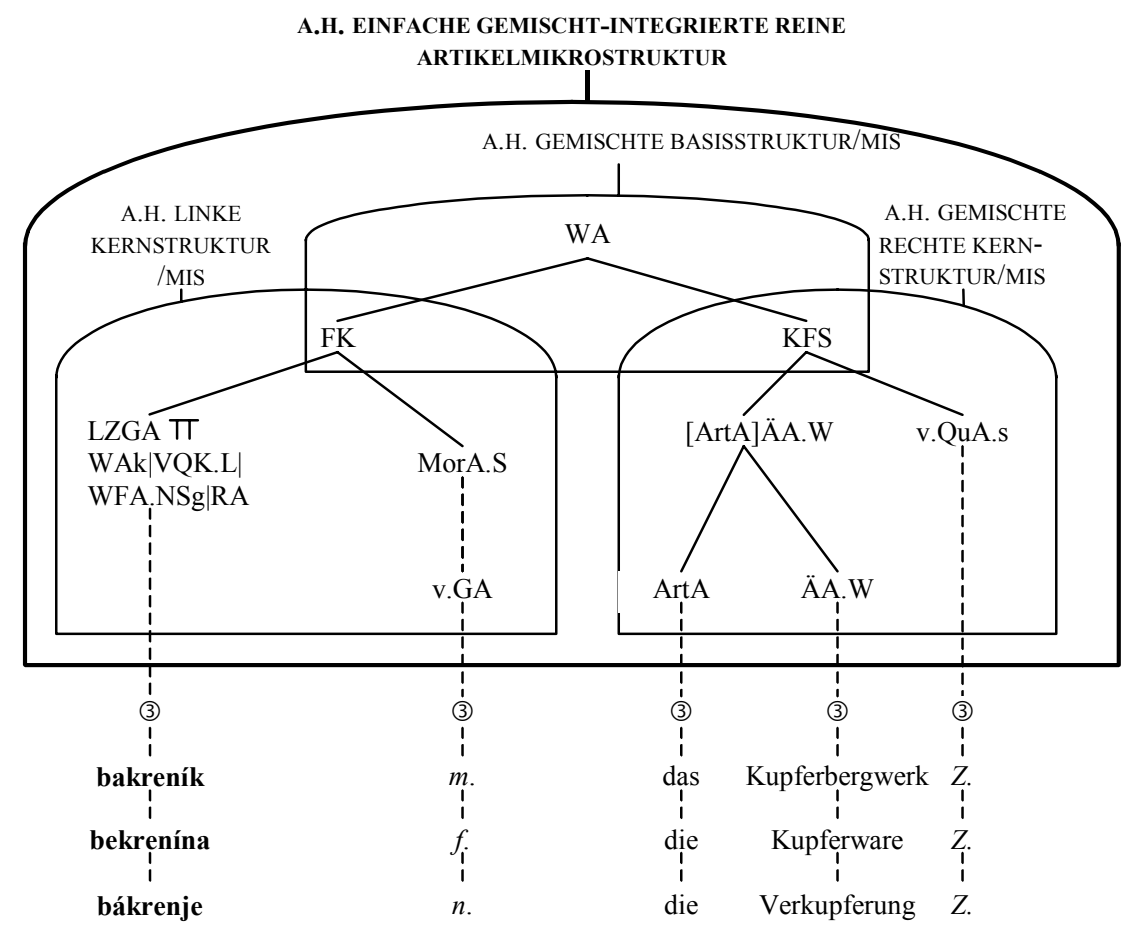

Abb. 2: Einfach kommentierter verdichteter Strukturgraph zur abstrakten hierarchischen (und den isomorphen konkreten hierarchischen) reinen Artikelmikrostrukturen, die $\mathrm{zu} \mathrm{wa}_{11}-\mathrm{wa}_{13}$ in Abb. 1 gehören. Darstellungskonventionen: „x $-\mathrm{y}^{\prime \prime}$ bedeutet (von unten nach oben gelesen) soviel wie $x$ ist eine Teilangabe von $y$; ", $\mathrm{x}---\mathrm{y}$ " bedeutet (von unten nach oben gelesen) soviel wie $x$ ist ein Element von y $(=\mathrm{x} \in \mathrm{y}) ;$ ", $\mathrm{x}--(3)--\mathrm{y}^{\prime \prime}$ bedeutet soviel wie die Element-Klassen-Beziehung besteht 3 mal. Abkürzungen: WA = Wörterbuchartikel; alle anderen Abkürzungen sind solche für Angabeklassen: FK = Formkommentar; KFS = Kommentar zur Form und Semantik; LZGA = Lemmazeichengestaltangabe; " $\Pi^{\prime \prime}=$ oben erweitert um; WAk $\mid$ VQK.L = Wortakzent- zugleich Vokalquanti- 
tätskennzeichnung zur Länge; "| |" = zugleich; WFA.NSg = Wortformangabe Nominativ Singular; RA = Rechtschreibangabe; MorA.S = Morphologieangabe beim Substantiv; v.GA = verdichtete Genusangabe; [Art A] ÄA.W = um eine Artikelangabe linkserweiterte Wortäquivalentangabe; ArtA = Artikelangabe; ÄA.W = Wortäquivalentangabe; v.QuA.s = verdichtete Angabe einer sekundären Quelle

Reine hierarchische Artikelmikrostrukturen sind Ordnungsstrukturen. In konkreter Ausprägung sind sie dadurch erhältlich, dass auf einer Trägermenge, deren Elemente alle Angaben und der ganze Wörterbuchartikel sind, zwei strukturprägende Relationen definiert werden, und zwar eine Relation vom Typ der Präzedenzrelation (mit dem Relationsterm $x$ geht $y$ voraus) sowie eine Relation vom Typ der partitiven Relation (mit dem Relationsterm $x$ ist eine Teilangabe von $y$ ). Bei der abstrakten Ausprägung sind die Elemente der Trägermenge Angabeklassen eines Wörterbuchs und die Klasse der Wörterbuchartikel. Die elementaren und nichtelementaren Angaben jedes Wörterbuchartikels sind durch eine Anwendung der Methode der nichtexhaustiven funktional-positionalen Segmentation erhältlich (vgl. z.B. Wiegand 2000a: 235ff u. 2005: 217ff). In den Wörterbüchern zu Sprachen, die mit einer Alphabetschrift verschriftet sind und in denen auf Zeilen von links nach rechts geschrieben wird, treten deutlich mehr als 200 Typen von hierarchischen Artikelmikrostrukturen auf. Der Typ der einfachen hierarchischen Artikelmikrostruktur gehört stets zu einem basalen Wörterbuchartikel; Artikel dieses Typs bestehen immer aus einem Formkommentar und einem unmittelbar folgenden Zweitkommentar, der unterschiedlich ausgeprägt sein kann. In Plet sind alle Zweitkommentare Kommentare zur Form und Semantik, weil nach dem Mikrostrukturenprogramm von Plet, das anhand der gegebenen textuellen Strukturen der Wörterbuchartikel vollständig rekonstruiert werden kann, im Zweitkommentar sowohl Angaben zur Form als auch solche zur Bedeutung vorgesehen sind. In den Kurzartikeln $\mathrm{wa}_{11}-\mathrm{wa}_{13}$ sind z.B. die nichtadjazent linksadressierten Wortäquivalentangaben Angaben zur Bedeutung und die adjazent rechtsadressierten Artikelangaben Angaben zur Form. Einfache Artikelmikrostrukturen heißen integriert - um es sehr allgemein und stark vereinfacht auszudrücken -, wenn allein die angesetzte Bedeutungsstruktur des Lemmazeichens die Struktur des Zweitkommentars bestimmt, so dass alle Angaben im textuellen Skopus einer bestimmten Bedeutungsangabe stehen (genauere Bestimmung z.B. in Meyer und Wiegand 2000: 91). Gemischt-integriert heißt eine Artikelmikrostruktur dann, wenn der zugehörige Wörterbuchartikel als Zweitkommentar keinen semantischen Kommentar, sondern einen Kommentar zur Form und Semantik aufweist.

$\mathrm{Zu}$ jedem Mikrostrukturtyp lässt sich ein allgemeines Mikrostrukturbild angeben. Allgemeine Mikrostrukturbilder sind nach festen Vorschriften erzeugte Ausschnitte aus Strukturgraphen für abstrakte hierarchische reine Artikelmikrostrukturen. Sie sind formale Darstellungsmittel und dienen dazu, den jeweiligen Mikrostrukturtyp, der zu einem Artikel gehört, schnell zu erkennen. 
Das allgemeine Mikrostrukturbild, das zu den Artikeln wa a $_{11}-\mathrm{wa}_{13}$ in Abb. 1 und zu Hunderten von weiteren Einzeilenartikeln in Plet gehört, die isomorphe Mikrostrukturen aufweisen, findet sich in Abb. 3.

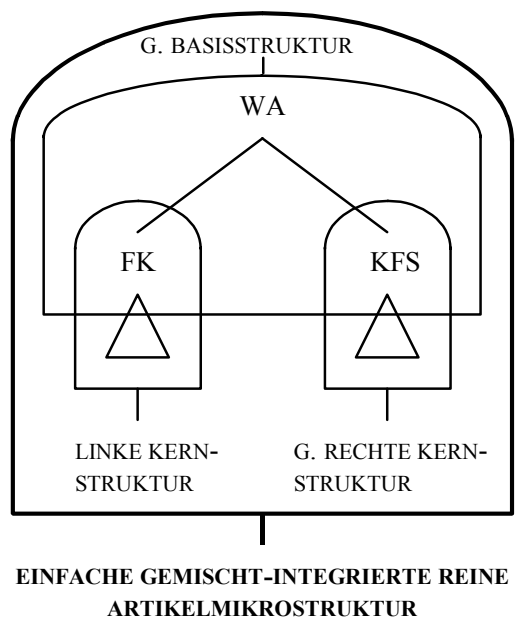

Abb. 3: Allgemeines Mikrostrukturbild zu gemischt-integrierten reinen Artikelmikrostrukturen, die zu basalen Wörterbuchartikeln mit monosemen Lemmazeichen gehören wie z.B. wa ${ }_{11}-\mathrm{wa}_{17}$ in Abb. 1. Abkürzungen: G = GEMISCHTE

$\mathrm{Zu}$ jedem allgemeinen Mikrostrukturbild kann ein einfaches Artikelstrukturschema angegeben werden. Solche Schemata erleichtern den Strukturvergleich der Mikrostrukturen unterschiedlicher Artikel. Das einfache Artikelstrukturschema, das zum allgemeinen Mikrostrukturbild in Abb. 3 und damit zu wa11$\mathrm{wa}_{13}$ und $\mathrm{zu}$ allen Artikeln angegeben werden kann, deren Mikrostruktur (MikS) zu den Mikrostrukturen von wa ${ }_{11}-w_{13}$ isomorph sind, lautet wie folgt: WA: (Miks) FK < KFS (mit „:" für besteht aus und "<" für geht voraus; der Index MikS kann in Kotexten weggelassen werden, in denen klar ist, dass es um Mikrostrukturen geht).

$\mathrm{Zu}$ Wörterbuchartikeln, die mindestens einen funktionalen Angabezusatz aufweisen, kann nicht nur eine reine, sondern stets auch eine hybride Artikelmikrostruktur in konkreter und abstrakter Ausprägung angegeben werden; hybrid heißen konkrete Artikelmikrostrukturen dann, wenn ihre Trägermengen nicht elementenhomogen sind, also ausschließlich Textkonstituenten enthalten, sondern wenn ihre Trägermengen elementenheterogen sind, weil ihre Elemente von verschiedener Herkunft sind, da sie sowohl durch eine Anwendung der Methode der funktional-positionalen als auch durch eine Anwendung der Methode der nichtfunktional-positionalen Segmentation sowie durch eine Anwendung der Methode der segmentativen Isolierung gegeben sind. - Im Folgenden werden anhand von wa $\mathrm{w}_{11}$ in Abb. 1 alle methodischen Schritte erläutert, die ausgeführt werden müssen, um eine hybride Artikelmikrostruktur zu erhalten. 
Mit funktionalen Angabezusätzen werden elementare Angaben oben oder unten oder binnen erweitert. Durch Angabenerweiterung mittels funktionaler Angabezusätze entstehen erweiterte elementare Angaben, die deswegen als elementar gelten, weil sie nicht durch eine Anwendung der funktional-positionalen Segmentation in mindestens zwei Angaben (restfrei) segmentiert werden können. Während Angaben funktional-positional isolierbare Textkonstituenten sind, also Textsegmente mit eigener Form, eigener genuiner Funktion sowie eigener textueller Position, gilt dies für funktionale Angabezusätze nicht, weil sie entweder keine eigene Position - wie die oben und unten erweiterten funktionalen Angabezusätze - aufweisen, oder weil sie - wie die binnenerweiterternden Glossate - zwar eine eigene textuelle Position aufweisen, aber funktional-positional nicht isolierbar sind. Durch die Angabenerweiterung erhalten elementare Angaben eine interne Angabestruktur, die systematisch analysiert werden kann, wie nachfolgend gezeigt wird, und zwar am Beispiel von wa $\mathrm{w}_{11}$. In diesem Kurzartikel ist die Lemmazeichengestaltangabe, nämlich „bakreník", eine elementare Angabe, die durch einen bifunktionalen Angabezusatz, nämlich eine Wortakzentkennzeichnung, oben erweitert ist, die zugleich eine Vokalquantitätskennzeichnung zur Länge ist. Der bifunktionale Angabezusatz ist durch einen Akut realisiert, der an das Angabeformsegment $\mathbf{i}$ hinabadressiert ist. Als elementare Angabe ist die als lemmatische Substantivangabe ausgeprägte oben erweiterte Lemmazeichengestaltangabe „bakreník" nicht funktional-positional segmentierbar. Um die Elemente ihrer internen Struktur zu ermitteln, muss sie durch eine Anwendung der Methode der segmentativen Isolierung segmentiert werden. Dabei werden horizontale Segmentationsschnitte so gelegt, dass die oben und die unten erweiternden funktionalen Angabezusätze vom Rest der erweiterten elementaren Angabe abgetrennt werden. Das Segmentationsergebnis besteht demgemäß aus dem Segment bakrenik und dem Akut, so dass zwei Teile einer erweiterten Angabe vorliegen. Um die zwar visuell deutlich erkennbare Position des Akuts über dem Angabeformsegment $\mathbf{i}$ auch auf einem methodischen Weg einwandfrei und eindeutig festlegen zu können, wird „bakreník“ mittels einer Anwendung der Methode der nichtfunktional-positionalen Segmentation so segmentiert, dass sich die folgenden drei Angabeformsegmente ergeben: bakren|í|k: hierbei sind die senkrechten Striche Segmentationsfugenmarkierungen. Das Segment bakren gehört zur Klasse der vorderen Angabeformsegmente (vAFSeg), so dass gilt: bakren $\in$ vAFSeg; i gehört zur Klasse der mittleren Angabeformsegmente (mAFSeg), so dass gilt: $\mathbf{i} \in \mathrm{mAFSeg}$. Schließlich gehört $\mathbf{k}$ zur Klasse der hinteren Angabeformsegmente (mAFSeg), und es gilt demgemäß die Aussage $\mathbf{k} \in$ hAFSeg. Weiterhin gelten die folgenden Aussagen: (i) bakren $<\mathbf{i}<\mathbf{k}$ sowie (ii) vAFSeg $<$ mAFSeg $<$ hAFSeg mit ",<" für geht voraus.

Führt man die erläuterten Segmentationsoperationen in entsprechender Weise bei den Lemmazeichengestaltangaben von $\mathrm{wa}_{12}$ und $\mathrm{wa}_{13}$ aus, dann erhält man folgende beiden Segmentationsergebnisse: bakren|í|na und $\mathbf{b}|\mathbf{a}|$ krenje. Für die Angabeformsegmente gelten die anhand von bakren $|\mathbf{i}| \mathbf{k}$ gemachten Aussagen mutatis mutandis. 
Um die zur konkreten internen Angabestruktur isomorphe abstrakte interne Angabenstruktur von "bakreník" in wa $\mathbf{w}_{11}$ in Abb. 1 angeben zu können, wird nachfolgend zunächst eine Trägermenge - sie heiße $\mathrm{M}_{\mathrm{Ar}}^{\mathrm{a}}$ (bakreník) für die zu bildende Angabestruktur gebildet; sie kann wie folgt angegeben werden: $\mathrm{M}_{\mathrm{Ar}}^{\mathrm{a}}$ (bakreník $)=\{\mathrm{mAFSeg}$, WAk $\mid$ VQK.L $\}$.

Diese Trägermenge enthält mithin zwei Elemente, die Klassen sind; sie gehört zu den elementenheterogenen Trägermengen, da nicht beide Klassen solche von Textkonstituenten sind. Im nächsten Schritt wird auf der Trägermenge eine zweistellige irreflexive und damit asymmetrische sowie transitive Relation - sie heiße $\mathrm{R}_{\mathrm{ob}}^{\mathrm{a}}$ (bakreník) - vom Typ der textarchitektonischen oberhalb-Relation definiert, zu der der Relationsterm $x$ ist oberhalb von y gehört, mit " $x$ " als Variable für oben erweiternde funktionale Angabezusätze und " $y$ " als Variable für Angabeformsegmente, die deren Bezugsadresse bilden; $\mathrm{R}_{\mathrm{ob}}^{\mathrm{a}}$ (bakreník) ist eine Teilmenge des Kartesischen Produktes der Trägermenge mit sich selbst, so dass gilt: $\mathrm{R}_{\mathrm{ob}}^{\mathrm{a}}$ (bakreník) $\subseteq \mathrm{M}_{\mathrm{Ar}}^{\mathrm{a}}$ (bakreník) $\mathrm{x}$ $\mathrm{M}_{\mathrm{Ar}}^{\mathrm{a}}$ (bakreník). Für das einfache Kreuzprodukt einer Menge $\mathrm{M}$ mit sich selbst wird im Folgenden $\mathrm{M}^{2}$ geschrieben. Die Relation prägt auf der Trägermenge eine Struktur, die zu den vertikalen Angabearchitekturen gehört. Strukturen, deren strukturprägende Relationen entweder oberhalb- oder unterhalb- oder links- oder rechts-Relationen sind, heißen in der Theorie der Wörterbuchform Architekturen. Vertikale Angabearchitekturen von oben oder unten erweiterten elementaren Angaben lassen sich mit den gleichen formalen Darstellungsmitteln darstellen wie die vertikalen Textarchitekturen von Wörterbuchartikeln (vgl. z.B. Wiegand 2001a: 191ff). In Abb. 4 findet sich das allgemeine Angabearchitekturbild für die oben um eine Wortakzentkennzeichnung, die zugleich eine Vokalquantitätskennzeichnung zur Länge ist, erweiterten Lemmazeichengestaltangaben in $\mathrm{wa}_{11}-\mathrm{wa}_{13}$.

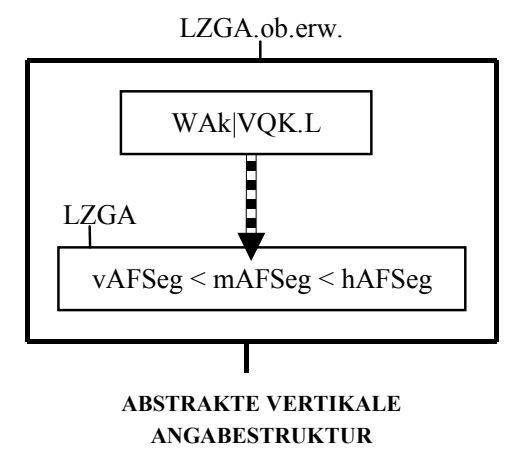

Abb.4: Allgemeines Angabearchitekturbild zu den oben erweiterten Lemmazeichengestaltangaben in wa $\mathrm{w}_{11}-\mathrm{wa}_{13}$ in Abb. 1; Darstellungskonventionen: "x $\mathrm{x} \rightarrow \mathrm{y}$ " bedeutet soviel wie $x$ ist oberhalb von $y$, wenn der Pfeil nach unten zeigt; Abkürzungen: vAFSeg $=$ vorderes Angabeformsegment; mAFSeg $=$ mittleres Angabeformsegment; hAFSeg = hinteres Angabeformsegment; WAk $\mid$ VQK.L = Wortakzent-, zugleich Vokalquantitätskennzeichnung zur Länge; LZGA.ob. erw. = oben erweiterte Lemmazeichengestaltangabe 
Die abstrakte vertikale Angabearchitektur, deren allgemeines Angabearchitekturbild in Abb. $4 \mathrm{zu}$ sehen ist, ist eine Teilstruktur der abstrakten (a) hierarchischen hybriden (hy) Angabestruktur (Ans), die zur Lemmazeichengestaltangabe "bakreník" in wa $\mathbf{k}_{11}$ gehört. Um diese Angabestruktur zu erhalten, benötigen wir zunächst eine geeignete Trägermenge, die alle Elemente der Angabestruktur enthält; diese heiße $\mathrm{M}_{\text {hyAns }}^{\mathrm{a}}$ (bakreník) und kann mit einer Mächtigkeit von $|6|$ wie folgt angegeben werden:

$$
\begin{aligned}
& \mathrm{M}_{\text {hyAns }}^{\mathrm{a}}(\text { bakreník })=\{\text { LZGA T WAk } \mid \text { VQK.L } \mid \text { WFA.NSg | RA, } \\
& \text { LZGA | WFA.NSg | RA, WAk | VQK.L, vAFSeg, mAFSeg, h.AFSeg\}. }
\end{aligned}
$$

Im nächsten Schritt werden auf dieser Trägermenge die folgenden drei strukturprägenden Relationen definiert:

(i) $\quad \mathrm{R}_{\mathrm{p}}^{\mathrm{a}}$ (bakreník), eine irreflexive (damit asymmetrische) und transitive Relation vom Typ der Präzedenzrelation mit dem Relationsterm $x$ geht $y$ voraus (mit , $x^{\prime \prime}$ und ", $y$ " als Variablen für Klassen von Textsegmenten); es gilt: $\mathrm{R}_{\text {ap }}^{\mathrm{a}}($ bakreník $) \subseteq\left(\mathrm{M}_{\text {hyAns }}^{\mathrm{a}}(\text { bakreník })\right)^{2}$

(ii) $\mathrm{R}_{\text {part }}^{\mathrm{a}}$ (bakreník), eine reflexive, asymmetrische und transitive Relation vom Typ der partitiven Relation mit dem Relationsterm $u$ ist ein Teil von $v$ (mit ", $u^{\prime \prime}$ und ", $v^{\prime \prime}$ als Variablen für Klassen von Textsegmenten; es gelten: $\mathrm{R}_{\text {part }}^{\mathrm{a}} \subseteq\left(\mathrm{M}_{\text {hyAns }}^{\mathrm{a}}(\text { bakreník })\right)^{2}$ sowie $\mathrm{R}_{\text {part }}^{\mathrm{a}}($ bakreník $) \cap \mathrm{R}_{\mathrm{p}}^{\mathrm{a}}($ bakreník) $=\varnothing$.

(iii) $\quad \mathrm{R}_{\mathrm{ob}}^{\mathrm{a}}$ (bakreník), eine textarchitektonische Relation vom Typ der oberhalbRelation mit dem Relationsterm $r$ ist oberhalb von $s$ (mit " $r^{\prime \prime}$ als Variable für oben erweiternde funktionale Angabezusätze und "s" als Variable für deren unten situierte Bezugsadressen); es gelten: $\mathrm{R}_{\mathrm{ob}}^{\mathrm{a}}$ (bakreník) $\subseteq$ $\left(\mathrm{M}_{\text {hyAns }}^{\mathrm{a}}(\text { bakreník })\right)^{2} ; \mathrm{R}_{\mathrm{ob}}^{\mathrm{a}}($ bakreník $) \cap \mathrm{R}_{\mathrm{p}}^{\mathrm{a}}($ bakreník $)=\varnothing ; \mathrm{R}_{\mathrm{ob}}^{\mathrm{a}}($ bakreník) $\cap \mathrm{R}_{\text {part }}^{\mathrm{a}}($ bakreník $)=\varnothing$.

Als Ergebnis der erläuterten Operationen ist die abstrakte hierarchische architektonisch angereicherte Angabestruktur der um eine Wortakzent- und Vokalquantitätskennzeichnung oben erweiterten Lemmazeichengestaltangabe „ba-

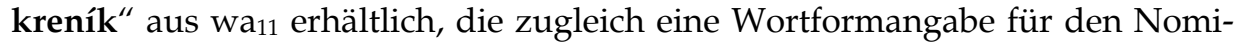
nativ Singular und eine Rechtschreibangabe ist.

Die in Abb. 5 dargestellte abstrakte hierarchische architektonisch angereicherte Angabestruktur ist isomorph zur konkreten hierarchischen architektonisch angereicherten Angabestruktur, die die Lemmazeichengestaltangabe "bakreník" in wa $\mathbf{w}_{11}$ in Abb. 1 aufweist. Diese konkrete Struktur ist auf dem gleichen methodischen Weg erhältlich wie die in Abb. 5 dargestellte abstrakte Struktur; lediglich die Elemente der Trägermenge sind keine Klassen, sondern konkrete Textsegmente oder Individuenname für diese. 


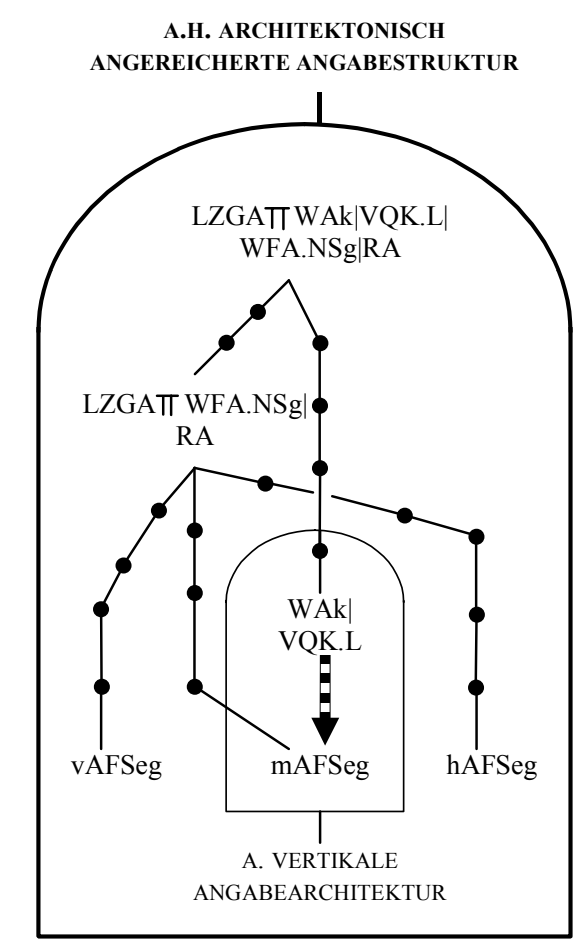

Abb. 5: Einfach kommentierter und mit architektonischen Komponenten angereicherter Strukturgraph zur abstrakten architektonisch angereicherten Angabestruktur, die zur Lemmazeichengestaltangabe in wa $\mathrm{w}_{11}$ gehört; Darstellungskonventionen: "u $\longrightarrow \cdots \mathrm{v}^{\prime \prime}$ bedeutet (von unten nach oben gelesen) soviel wie $u$ ist ein Teil von v; Abkürzungen: A = ABSTRAKTE

Die in Abb. 5 präsentierte Angabestruktur ist eine Teilstruktur der abstrakten hierarchischen einfachen gemischt-integrierten hybriden Artikelmikrostruktur, die zu wa ${ }_{11}$ in Abb. 1 gehört. Diese Artikelmikrostruktur ist auf der Darstellungsebene dadurch erhältlich, dass man die in Abb. 5 dargestellte abstrakte hierarchische architektonisch angereicherte Angabestruktur in die in Abb. 2 dargestellte Artikelmikrostruktur integriert; anders ausgedrückt heißt das: Die beiden Strukturgraphen werden strukturadäquat kontaminiert. Der klassische Weg für die Bildung der abstrakten hierarchischen einfachen gemischt-integrierten hybriden Artikelmikrostruktur, die zu wa ${ }_{11}$ gehört, besteht allerdings darin, dass man die Trägermenge der in Abb. 2 dargestellten reinen Artikelmikrostruktur (die sich - nebenbei bemerkt - aus der Abb. 2 leicht ablesen lässt) um die folgenden fünf Klassen von Textsegmenten erweitert: LZGA TT WFA.NSg|RA, WAk|VQK.L, vAFSeg, mAFSeg und hAFSeg. Dies sind die Textsegmentklassen, zu denen die Textsegmente gehören, die erhältlich sind, wenn man — wie oben gezeigt — die Lemmazeichengestaltangabe 
„bakreník“ zuerst mittels einer Anwendung der Methode der segmentativen Isolierung und daraufhin mittels einer Anwendung der Methode der nichtfunktional-positionalen Segmentation in Textsegmente zerlegt. Die elementenheterogene Trägermenge für die abstrakte hybride Artikelmikrostruktur — sie heiße $\mathbf{M}_{\text {hyMiS }}^{\mathrm{a}}$ (bakreník) — kann entsprechend mit einer Mächtigkeit von |15| wie folgt angegeben werden:

$$
\begin{aligned}
& \mathrm{M}_{\text {hymiS }}^{\mathrm{a}}(\text { bakreník) }=\text { (WA, FK, KFS, LZGA T WAk } \mid \text { VQK.L } \mid \text { WFA.NSg } \mid \\
& \text { RA, MorA.S, [ArtA]ÄA.W, v.QuA.s, v.GA, ArtA, ÄÄ.W, LZGA } \\
& \text { WFFA.NSg |RA, WAk | VQK.L, vAFSeg, mAFSeg, hAFSeg\}. }
\end{aligned}
$$

Auf $\mathrm{M}_{\text {hyMis }}^{\mathrm{a}}$ (bakreník) wird dann eine Relation vom Typ der Präzedenzrelation, eine vom Typ der partitiven Relation mit dem Relationsterm $x$ ist eine Teilangabe von y (mit , $x x^{\prime \prime}$ als Variable für Angaben und mit ", $y$ " als Variable für Angaben und Wörterbuchartikel), eine weitere Relation vom Typ der partitiven Relation mit dem Relationsterm $u$ ist ein Textsegment (ohne Textkonstituentenstatus) von $v$ sowie eine textarchitektonische Relation vom Typ der oberhalbRelation definiert. Nach Ausführung dieser Operationen ergibt sich die in Abb. 6 auszugsweise dargestellte abstrakte hierarchische einfache gemischt-integrierte hybride Artikelmikrostruktur, die zu wa ${ }_{11}$ in Abb. 1 gehört. Die Struktur ist deswegen nur auszugsweise dargestellt, weil die zum KFS gehörige gemischte rechte Kernstruktur als Teilstruktur der Artikelmikrostruktur mit der in Abb. 2 dargestellten Kommentarstruktur, nämlich der abstrakten hierarchischen gemischten rechten Kernstruktur, identisch ist.

Weit über die Hälfte der Substantiv-, Adjektiv- und Verbartikel in Plet gehören zum Typ des basalen Wörterbuchartikels mit Kommentar zur Form und Semantik (i.S.v. Wiegand 2003: 263f), so dass das mikrostrukturelle Artikelstrukturschema WA : FK < KFS und das allgemeine Mikrostrukturbild in Abb. 3 für sie gilt. Werden Homonyme als Lemmata angesetzt, erhält der zugehörige Kurzartikel eine topikalisierte Homonymenangabe; da die Homonymie eine Bedeutungsbeziehung zwischen $n$ sprachlichen Zeichen ist (mit $n \geq 2$ ), ist eine Homonymangabe keine Formangabe und somit keine Teilangabe des Formkommentars: Demgemäß stehen die Homonymenangaben in $\mathrm{wa}_{22}$ und $w_{23}$ sowie in $w_{30}$ und $w_{31}$ in Abb. 1 im Präkommentar (PräK), so dass linkserweiterte Artikel vorliegen, zu denen das mikrostrukturelle Artikelstrukturschema WA : PräK < FK < KFS und das allgemeine Mikrostrukturbild in Abb. 7 gehören. - In relativ vielen Kurzartikeln steht nach dem nichttypographischen Mikrostrukturanzeiger "- " eine lemmatisch orientierte vollständige Verweisangabe, wie z.B. in $\mathrm{wa}_{23}$ die polyadressierte Verweisangabe "prim. klenovec, klinovina" und in wa $\mathrm{w}_{33}$ die monoadressierte Verweisangabe "prim. glinavec". Da die zugehörigen Verweisungen sich jeweils auf das gesamte sprachliche Zeichen und damit auf die Form und Bedeutung beziehen, sind diese Verweisangaben Teilangaben des Kommentars zur Form und Semantik und stehen nicht im Postkommentar eines rechtserweiterten Artikels, sondern in einer finalen Verweisposition des KFS eines basalen Wörterbuchartikels. 


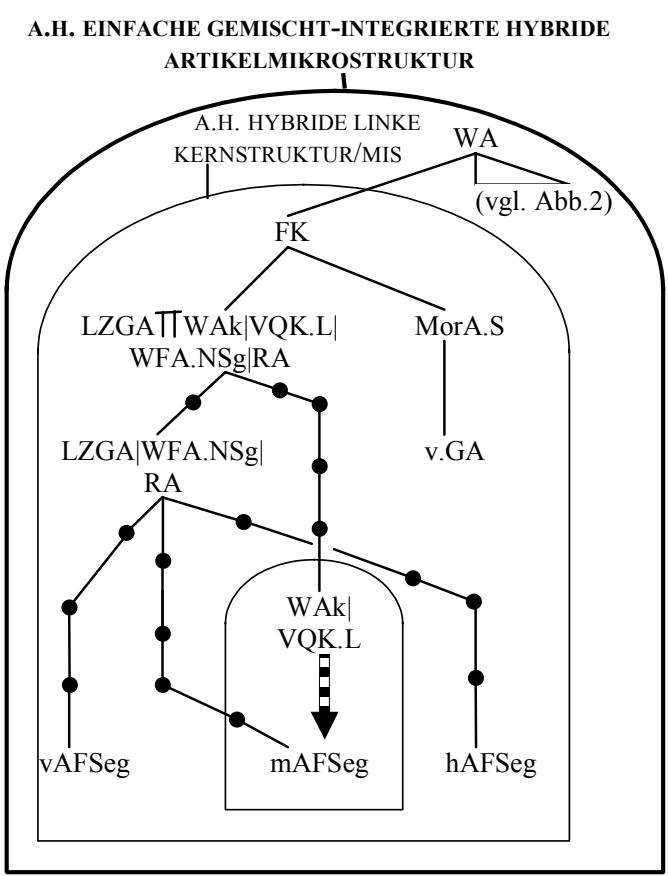

Abb. 6: Nicht vollständig ausgeführter Strukturgraph zur abstrakten hierarchischen einfachen gemischt-integrierten hybriden Artikelmikrostruktur, die zu wa 11 gehört

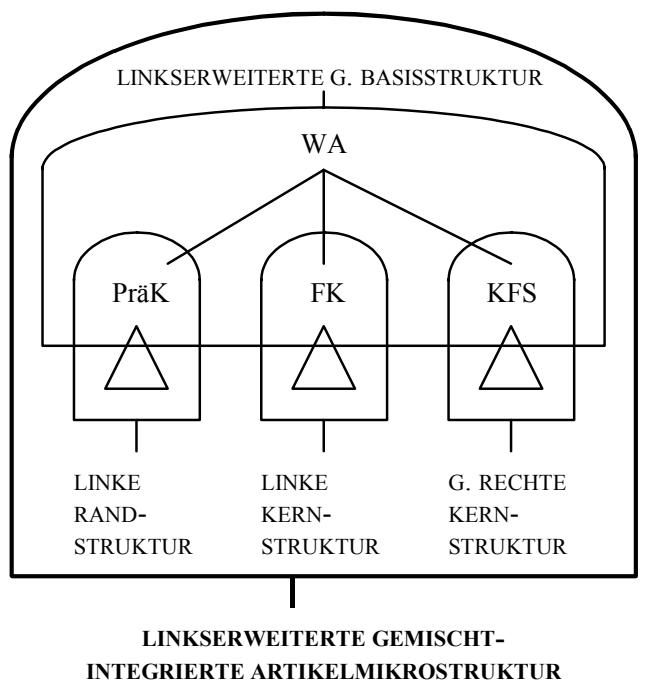

Abb. 7: Allgemeines Mikrostrukturbild zu gemischt-integrierten reinen Artikelmikrostrukturen, die zu linkserweiterten Wörterbuchartikel (wie z.B. $w_{22}$ u. $w_{23}$ in Abb. 1) gehören 
In Abb. 8 werden die abstrakte (und isomorphe konkrete) linkserweiterte gemischt-integrierte reine Artikelmikrostrukturen dargestellt.

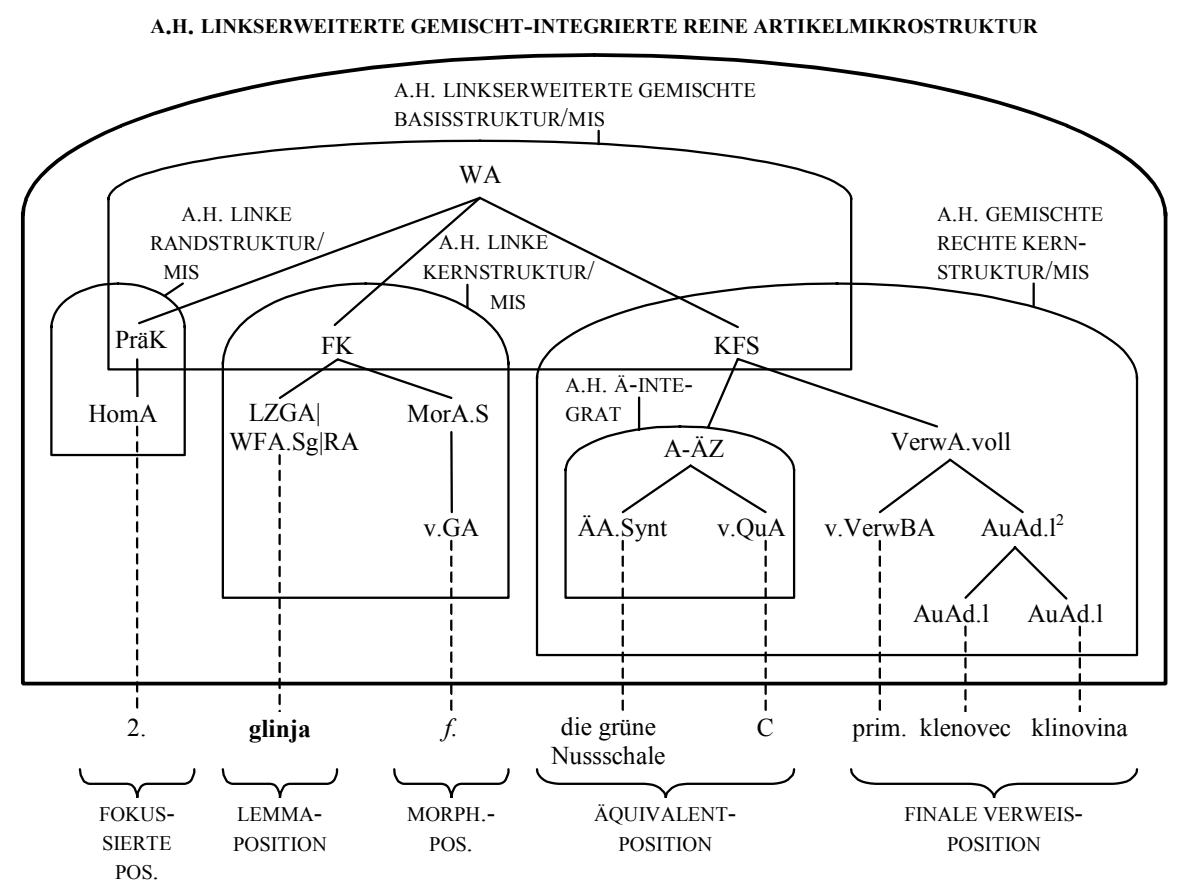

Abb. 8: Erweitert kommentierter Strukturgraph zur abstrakten (und isomorphen konkreten) linkserweiterten gemischt-integrierten reinen Artikelmikrostruktur, die zu wa ${ }_{23}$ in Abb. 1 gehören; Abkürzungen: A. = ABSTRAKTE; $\mathrm{H}=$ HIERARCHISCHE; POS. = POSITION; Ä-INTEGRAT = ÄQUIVALENT-INTEGRAT; AuAd. $1^{2}$ = homosegmentäre lemmatische Außenadressenangabe, die aus zwei Außenadressenangaben besteht; VerwA.voll = vollständige Verweisangabe; v.VerBA = verdichtete Verweisbeziehungsangabe; v.QuA = verdichtete Quellenangabe

Die erweiterten Kommentierungen unterhalb des Strukturgraphen in Abb. 8 bestehen aus Namen für die mikrostrukturellen Artikelpositionen; diese sind Ausschnitte aus der präzedentiven Artikelmikrostruktur. $\mathrm{Zu}$ einer mikrostrukturellen Artikelposition gehören Angaben (und in partiell kondensierten Artikeln auch Angabetexte), die in sprachtheoretischer und/oder metalexikographischer Perspektive zusammengehören (vgl. Wiegand 2000a: 242f).

Im Folgenden werden einige Bemerkungen zum Wörterbuchgegenstand und damit zum Datenangebot in den Kurzartikeln von Plet gemacht. Ob das Datenangebot eines Wörterbuchs angemessen ist, lässt sich nur relativ zum Wörterbuchtyp und relativ zu den angesetzten Wörterbuchfunktionen (i.S.v. Wiegand 2001) feststellen. Wir wissen bereits, dass Plet kein typisches allge- 
meinsprachliches zweisprachiges Wörterbuch ist. Über die Wörterbuchfunktionen findet man in den Metatexten dieses Wörterbuchs nichts Weiterführendes. Deutlich ist nur, dass Plet ein Wörterbuch für potenzielle Benutzer mit Slowenisch als Muttersprache ist. Für solche Benutzer, die Plet als zweisprachiges Wörterbuch in Situationen der Hinproduktion oder in Situationen der Hinübersetzung nutzen möchten, ist dieses Wörterbuch allerdings relativ schlecht geeignet, wie im Folgenden kurz dargelegt werden soll.

Der slowenische Benutzer findet bei vielen deutschen Äquivalenten eine veraltete Schreibung, z.B. tritt durchgängig th-Schreibung auf, so in $\mathrm{wa}_{20}$,"thonhältig", in wa 11 "Thon", in wa 29 "Thongräber" oder s.v. „bájanica" "Wünschelruthe“; oder statt initialem $k \mid K$ steht $c \mid C$, z.B. s.v. „istobítnost" "Consubstantialität" oder s.v. „istonárodən“" „Connational“; weiterhin finden sich statt der Umlautbuchstaben häufig Schreibungen von Vokalbuchstabe + e, z.B. s.v. "glicerīn" "Oelsüß" oder s.v. „istomộčnica" "Aequivalentzahl“. Häufig findet sich statt $z \mid Z$ der Buchstabe $c \mid C$, z.B. s.v. „istoviti“ „identificieren“, s.v. „bakreníca" "Cementwasser". Öfters finden sich Umlautschreibungen, wenn im Standarddeutsch Umlaut nicht üblich ist, z.B. "thonhältig“ s. v. "glinovàt" oder „kupferfärbig“ s.v. „bákrast". Die genannten Fälle sind keine Einzelfälle, sondern es gibt jeweils Hunderte. Offensichtlich wurde hinsichtlich der Orthographie Quellentreue angestrebt. Neben einer vollständig veralteten Orthographie findet sich aber auch die neueste, z.B. in wa ${ }_{23}$ "Nussschale" (mit 3 s!). Schlimmer als dieses orthographische Durcheinander ist aber, dass man Hunderte von deutschen Äquivalenten findet, die kein Deutscher, der seine Sprache beherrscht, kennt und die auch in keinem der einschlägigen deutschen Wörterbücher des heutigen Deutsch (wie z.B. Duden- ${ }^{3} \mathrm{GW}$ oder Wahrig-8 DW) belegbar sind. Hier nur einige Beispiele: Keuschlerstand als Äquivalent zu bâjtarstvọ, Fackelschuh als Äquivalent zu bákətnik und absprecherisch als Äquivalent zu sódč’ $ə n$. Viele Äquivalente sind veraltet und in deutschen Wörterbüchern entsprechend markiert, z.B. Oelsüß als Äquivalent zu glicerinn (vgl. Duden${ }^{3} \mathrm{GW}$ ). Häufig werden bei Substantiven veraltete Formen des Nominativ Singular verwendet, wie z.B. "Mytholog" oder "Glaubensgenoss". Oft sind auch die Syntagmaäquivalente im heutigen Deutsch nicht bekannt wie z.B. "mit Brettern und Balken aussteifen" als Äquivalent zu bâjtati. Viele Komposita, die als Äquivalente genannt werden, sind zwar im Deutschen bildbar, aber ungebräuchlich wie z.B. Wasserschlamm als Äquivalent zu glîb, Mitmagd als Äquivalent zu sodékla, oder Mittheilnehmerin als Äquivalent zu sodẹlę̌znica.

Wollte man die Kurzartikel in Plet so bearbeiten, dass aus ihnen Kurzartikel werden, die ein slowenischer Benutzer in Situationen der Hinübersetzung und in Hinproduktionsituation erfolgreich nutzen könnte, wären mindestens die Folgenden Veränderungen nötig:

einheitliche neueste deutsche Orthographie bei allen mit Äquivalentangaben genannten Äquivalenten 
- Ergänzung der morphologischen Angaben bei allen Äquivalentangaben, und zwar: verweisvermittelnde Deklinationsmusterangaben bei Substantiven, Konjugationsklassenangaben (regelmäßig vs unregelmäßig) und andere Verbklassenangaben bei Verben, Angaben zur unregelmäßigen Graduierung bei Adjektiven

- Kollokationsangaben und Synonymangaben in Substantiv-, Verb- und Adjektivartikeln

— Verzicht auf die rudimentären Quellenangaben.

Die vorgeschlagenen Veränderungen sind ein Minimalprogramm für eine modernisierte Neuauflage. Sie lassen sich hinsichtlich der Wörterbuchform unterschiedlich realisieren. Für Substantivartikel ist z.B. eine Angabe zur Äquivalenz (A-Äz) optimal, die obligatorisch aus einer adjazent rechtsadressierten Artikelangabe (ArtA), mindestens einer Äquivalentangabe (entweder ÄA.W od. ÄA.Synt) besteht, sowie aus einer umtextorientierten numerischen verweisvermittelnden Deklinationsmusterangabe (DekMA). Die Wortäquivalentangaben müssen durch Silbentrennungsangaben binnenerweitert und durch Wortakzentkennzeichnungen, die zugleich Vokalquantitätskennzeichnung sind, unten erweitert sein. Fakultativ folgt eine Angabe eines äquivalenten Kollokationspaares (A.Koll.P.ä) oder eine entsprechende homosegmentäre Angabe (A.KollP.ä2, mit $n \geq 2$ ) und/oder eine Angabe eines äquivalenten Kompetenzbeispielpaares (A.KbeiP.ä).

Beispielsweise der Artikel wa ${ }_{34}$ in Abb. 1 könnte so umgeschrieben werden, das z.B. folgender Artikel wa' ${ }_{34}$ gegeben ist:

wa' ${ }_{34}$ : sočûtje, $n$. das Mit|ge|fühl 11\| die Sym|pa|thie, $19 \|$ e do bolnih Mitgefühl für Kranke

Anhand der als reduzierte Verweisangaben "11“ und "19“ ausgeprägten numerischen umtextorientierten verweisvermittelten Deklinationsmusterangaben, kann der Benutzer-in-actu einen umtextorientierten Verweis erschließen, dessen Befolgung durch die Ausführung einer externen Verweisbefolgungshandlung (i.S.v. Wiegand 1998: 408ff) ihn zu den numerischen Umtexteingängen 11 und 19 bringt, die Elemente einer numerischen äußeren Umtextzugriffsstruktur sind, die auf Deklinationsmuster Zugriff eröffnen, die Teile von Deklinationstabellen sind; diese könnten beispielsweise ähnlich gestaltet sein wie die im Wahrig- ${ }^{8}$ DW. Dies bedeutet zugleich, dass in einer Neuauflage von Plet eine tabellarische Wörterbuchgrammatik mit mehreren äußeren Umtextzugriffsstrukturen vorzusehen wäre.

Die abstrakte (und konkrete isomorphe) hierarchische einfache gemischtintegrierte reine Artikelmikrostruktur, die zu wa' ${ }_{34}$ gehören, sind in Abb. 9 dargestellt. 


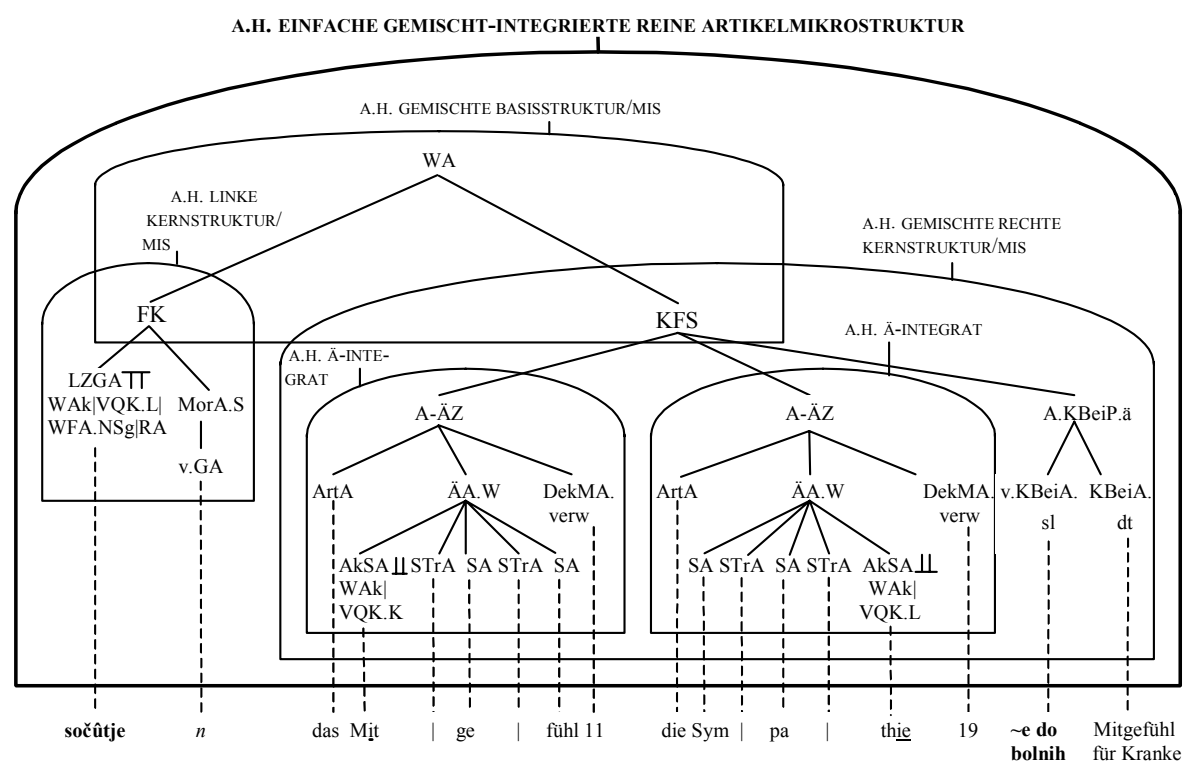

Abb. 9: Einfach kommentierter Strukturgraph zur abstrakten (und konkreten isomorphen) hierarchischen einfachen gemischt-integrierten reinen Artikelmikrostrukturen, die zu wa's4 gehören; Abkürzungen: AkSA = Akzentsilbenangabe, AkSA $\Perp$ WAk $\mid$ VQ.K.L = Akzentsilbenangabe, unten erweitert um eine Wortakzent- zugleich Vokalquantitätskennzeichung zur Länge; SA = Silbenangabe; STrA = Silbentrennungsangabe; DekMA.verw = verweisvermittelnde Deklinationsmusterangabe; AkSA $\Perp$ WAk $\mid$ VQA.L = Akzentsilbenangabe, unten erweitert um eine Wortakzent- zugleich Vokalquantitätskennzeichnung zur Länge; A.KBeiP.ä = Angabe eines äquivalenten Kompetenzbeispielpaares; v.KBeiA.sl = verdichtete slowenische Kompetenzbeispielangabe; KBeiA.dt = deutsche Kompetenzbeispielangabe.

Mit der großen Mehrzahl der Lemmata in Plet werden Lemmazeichen genannt, die als monoseme Wörter interpretiert sind. Als polysem interpretierte Lemmazeichen treten viel seltener auf. Im Folgenden betrachten wir die textuellen Strukturen von $\mathrm{wa}_{1}$ in Abb.1, dem Verbartikel zum Lemmazeichen glęštati, das als zweifach polysem interpretiert ist. Nach dem aus den Verbartikeln von Plet erschließbaren Mikrostrukturprogramm gilt: Formangaben zu den deutschen Äquivalentangaben sind - im Unterschied zu den Substantivartikeln - im Zweitkommentar nicht vorgesehen. Deswegen weisen die Verbartikel als Zweitkommentar auch keinen Kommentar zur Form und Semantik, sondern einen semantischen Kommentar auf.

Bei allen nachfolgenden Strukturanalysen wird der Prozess der Strukturbildung nicht mehr erläutert, sondern es werden nur dessen Ergebnisse präsentiert. Das allgemeine Mikrostrukturbild von wa ${ }_{1}$ ist in Abb. $10 \mathrm{zu}$ sehen. 


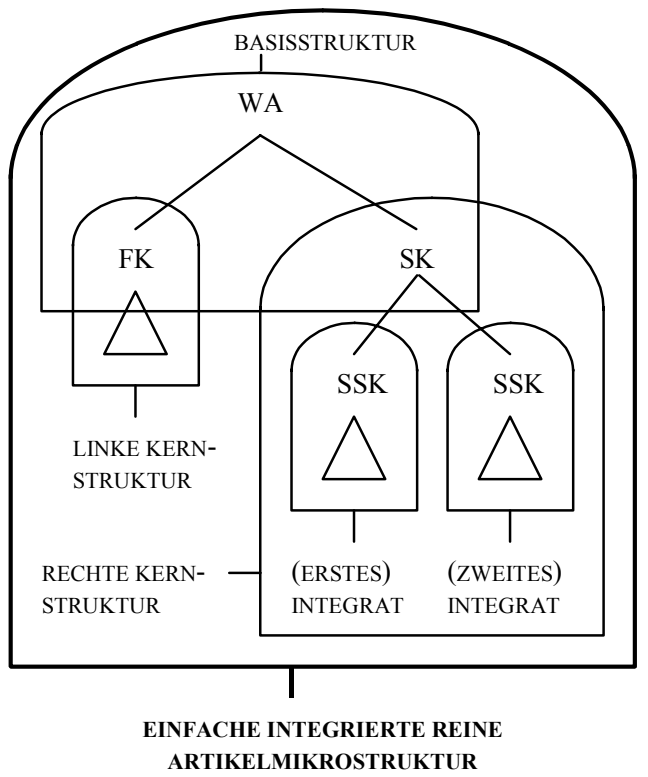

Abb. 10: Allgemeines Mikrostrukturbild zu integrierten reinen Artikelmikrostrukturen, die zu basalen Wörterbuchartikeln zu zweifach polysemen Lemmazeichen gehören; Abkürzungen: SK = semantischer Kommentar; SSK = semantischer Subkommentar

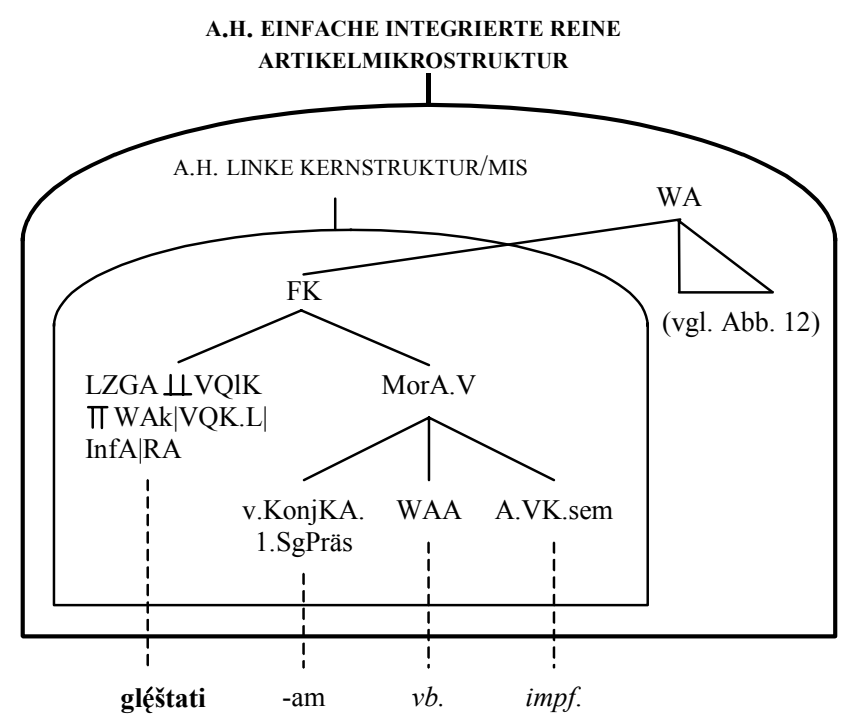

Abb. 11: Einfach kommentierter Strukturgraph zur abstrakten (und isomorphen konkreten) linken Kernstruktur als Teil der abstrakten hierarchischen integrierten reinen Artikelmikrostruktur; Abkürzungen: VQIK = Vokalqualitätskennzeich- 
nung; InfA = Infinitivangabe; v.KonjKA = verdichtete Konjugationsklassenangabe; A.VK.sem = Angabe der semantischen Verbklasse

Das erweiterte Artikelstrukturschema, das zu dem allgemein Mikrostrukturbild in Abb. 10 gehört, hat die folgende Form: WA: ${ }_{(\text {Mis) }}$ FK $<$ SK[SSk $<$ SSK].

Das Datenangebot im Formkommentar in den Verbartikeln in Plet ist relativ zum Typ des verbalen Lemmazeichens weitgehend einheitlich, so dass die in Abb. 11 dargestellten hierarchischen linken Kernstrukturen (nämlich die abstrakte und die konkrete) zu vielen entsprechenden linken Kernstrukturen isomorph sind. Dies bedeutet auch, dass die Formeigenschaften von Verben in den Verbartikeln meistens einheitlich lexikographisch bearbeitet wurden.

Die Kommentarstrukturen, die zum Formkommentar von wa ${ }_{1}$ gehören, also die linken Kernstrukturen, sind als Teilstrukturen der abstrakten hierarchischen und isomorphen konkreten einfachen integrierten reinen Artikelmikrostrukturen in Abb. 11 dargestellt.

Im Folgenden betrachten wir einige Auffälligkeiten im semantischen Kommentar von $\mathrm{wa}_{1}$. Im ersten semantischen Subkommentar wird das $\mathrm{zu}$ glẹštati gehörige reflexive Verb mit der verdichteten Verbangabe "g. se" genannt. Im zweiten semantischen Subkommentar finden sich zwei slowenische Kompetenzbeispielangaben, zu denen es keine deutschen Entsprechungen gibt; dies ist kein Einzelfall, und hier zeigt sich, dass Plet kein konsequent bearbeitetes bilinguales Wörterbuch ist, sondern, dass das Interesse in erster Linie der slowenischen Sprache gilt (vgl. 3). Dass das reflexive Verb im ersten semantischen Subkommentar präsentiert wird, ist wohl seiner Bedeutung geschuldet. Es stellt sich hier aber auch eine grundsätzliche Frage, nämlich die nach dem Verhältnis von Makrostruktur und Mikrostruktur in zweisprachigen Wörterbüchern, auf die wir zurückkommen. Die abstrakte (und die konkrete isomorphe) hierarchische rechte Kernstruktur sind als Teilstrukturen der einfachen integrierten reinen Artikelmikrostrukturen, die zu wa ${ }_{1}$ in Abb. 1 gehören, in Abb. 12 dargestellt.

Wie angekündigt, kommen wir im Folgenden auf das Problem des Verhältnisses von Makrostruktur und Mikrostruktur in zweisprachigen Wörterbüchern zurück; dies wird am Beispiel von wa ${ }_{36}$ in Abb. 1 mit dem Lemma glista diskutiert. Dabei wird auf den neueren Begriff der Makrostruktur zurückgegriffen, wie er in Wiegand (2008: 230ff) eingeführt wurde. Danach muss zwischen der alphabetischen Makrostruktur und der bzw. den alphabetischen Zugriffsstruktur(en) unterschieden werden. Für die Makrostruktur ist kriterial, dass sie die typspezifische makrostrukturelle Abdeckung eines Wörterbuchs und damit einen genau angebbaren Teil der lexikographischen Abdeckung vollständig anzeigt. Eine Makrostruktur kann mit der äußeren alphabetischen Hauptzugriffsstruktur identisch sein. In diesem Fall liegt eine monoalphabetische Makrostruktur vor. Eine Makrostruktur kann aber auch eine geordnete Menge von solchen äußeren alphabetischen Zugriffsstrukturen sein, deren äußere Zugriffstextelemente zur makrostrukturellen Abdeckung einen Beitrag leisten. Dann liegt eine polyalphabetische Makrostruktur vor. Im Meta- 


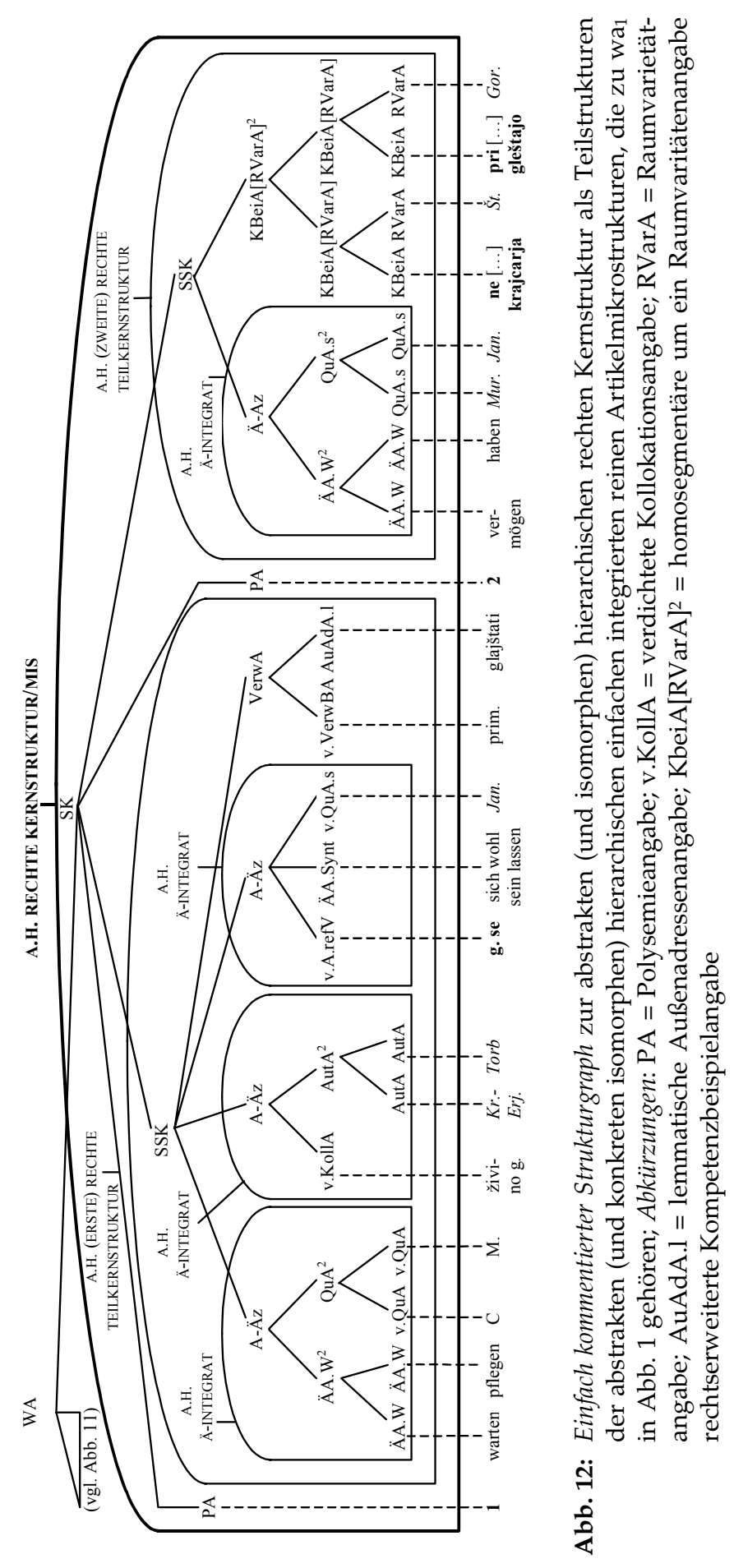


text von Plet erhält man keine Hinweise, wie das im Folgenden näher zu erläuternde Problem zu lösen ist. In $\mathrm{wa}_{36}$ finden sich mehrere verdichtete Mehrwortangaben, anhand derer slowenische Mehrwortbenennungen erschließbar sind, zu denen es im Deutschen äquivalente Komposita gibt, die mit Wortäquivalentangaben genannt werden. Beispielsweise ist „navadna g., der Spulwurm" eine lexikographische Bearbeitungseinheit: Die anhand der verdichteten Mehrwortangabe "navadna g." erschließbare Mehrwortbenennung navadna glísta wird mit der linkserweiterten Wortäquivalentangabe "der Spulwurm“ lexikographisch bearbeitet. Das bedeutet, dass „navadna g." zur lexikographischen Abdeckung einen Beitrag leistet. Entsprechendes gilt für die fünf alphabetisch folgenden verdichteten Mehrwortangaben, nämlich „otročja g.“, "konjska g." , ,ovčja g.“, ,"svinjska g.“ und „ribja g.". Es muss daher die Frage beantwortet werden: Sind die insgesamt sechs verdichteten Mehrwortangaben als Sublemmata zu betrachten? Wenn ja, dann wären sie Elemente der Makrostruktur und leisteten einen Beitrag zur makrostrukturellen Abdeckung; dies hätte weiterhin zur Folge, dass wa 36 ein Artikelnest wäre; navadna g. wäre dann das erste von sechs Nestlemmata, mit denen die alphabetische Ordnung durchbrochen wird, denn "glístast", das Lemma von wa 37 , kommt alphabetisch vor „navadna g.“. Insgesamt hätte man dann eine nestalphabetische Makrostruktur, die mit einer nestalphabetischen Hauptzugriffsstruktur identisch ist. Gegen diese Lösung spricht vor allem das Angabentupel „1), 2)“ in wa 36 .

Eine zweite Lösung lässt sich wie folgt erläutern: Plet weist eine glattalphabetische Makrostruktur auf, die mit einer glattalphabetischen Hauptzugriffsstruktur identisch ist. Die alphabetischen geordneten verdichteten Angaben der Mehrwortbenennungen sind nichtlemmatische Angaben und bilden zusammen mit dem kontinuierlichen Lemma glísta, zu dem die oben erweiterte Lemmazeichengestaltangabe "glísta" gehört, eine alphabetische innere Schnellzugriffsstruktur im Artikel wa w6 $_{36}$ Die makrostrukturelle Abdeckung wird dann auf der Basis der glattalphabetisch geordneten Lemmata berechnet. Um die lexikographische Abdeckung insgesamt zu berechnen, müssen dann alle zur Mikrostruktur gehörigen Angaben, mit denen artikelintern lexikalisierte slowenische Ausdrücke genannt werden und die auch an einer alphabetischen Stelle in die Makrostruktur eingeordnet sein könnten, wie z.B. glęštati se (vgl. wa $\mathbf{w}_{1}$ ) in der G-Lemmastrecke und navadna glísta (vgl. wa ${ }_{36}$ ) in der N-Lemmastrecke, berücksichtigt werden. In zweisprachigen Wörterbüchern heißen Angaben, mit denen lexikalisierte Ausdrücke der lexikographischen Ausgangssprache genannt werden, die bei einem anderen Lemmasatzprogramm als Elemente der Makrostruktur auftreten können und dann einen Beitrag zu makrostrukturellen Abdeckung leisten würden, makrostrukturelle Inseln (vgl. Meyer und Wiegand 2000: 140). Diese werden bei der Berechnung der lexikographischen Abdeckung berücksichtigt.

Damit kennen wir die für Plet charakteristischen textuellen Strukturen und wesentliche Teile des Datenangebots. Als zweisprachiges Wörterbuch ist Plet für Slowenen in Produktions- und Übersetzungssituationen und für Deut- 


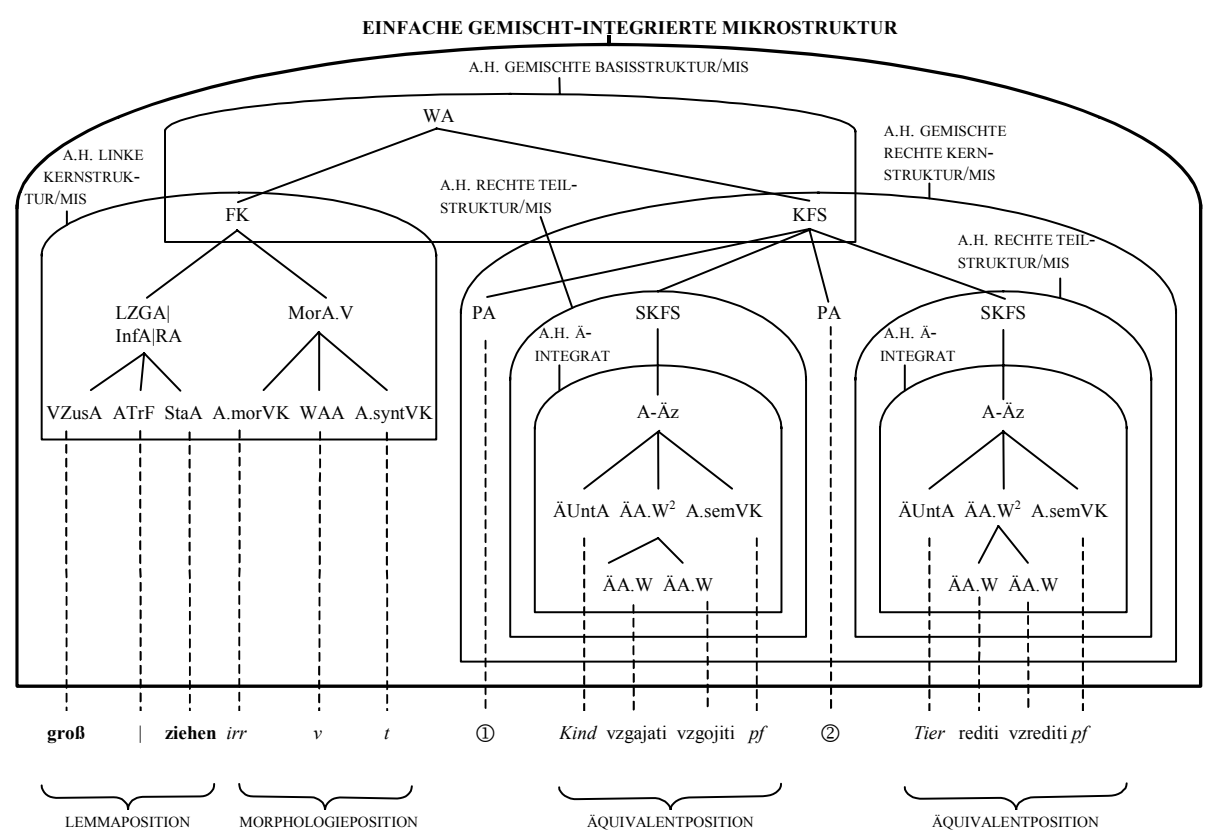

Abb. 14: Erweitert kommentierter Strukturgraph zur abstrakten (und isomorphen konkreten) hierarchischen einfachen gemischt-integrierten Artikelmikrostruktur, die wa $_{39}$ in Abb. 13 aufweist; Abkürzungen: VZusA = Verbzusatzangabe; ATrF = Angabe der Trennungsfuge (zugleich Partikelverbidentifizierungsangabe); StA = Stammangabe; A.morVK = Angabe der morphologischen Verbklasse; A.syntVK = Angabe der syntaktischen Verbklasse; ÄUntA = Äquivalentunterscheidungsangabe; SKFS = Subkommentar zur Form und Semantik; A.semVK = Angabe der semantischen Verbklasse; WAA = Wortangabe; $\ddot{A A} . W^{2}=$ homosegmentäre Wortäquivalentangabe, die aus zwei Wortäquivalentangaben besteht

Es folgen einige Bemerkungen $\mathrm{zu} \mathrm{wa}_{39}$ in $\mathrm{Abb}$. 13. Das erweiterte Artikelstrukturschema lässt sich aus Abb. 14 ablesen; es hat die Form WA:FK < KFA[SKFS < SKFS]. Dieses Strukturschema gehört zu zahlreichen Verbartikeln zu Verben, die als zweifach polysem interpretiert sind, z.B. zu wa 44 in Abb. 13 und zu den Artikeln zu den Verben anspannen, anspornen, abblasen, abfragen und abrichten in PonsN. Bei als polysem interpretierten Ausdrücken finden sich meistens kursiv gesetzte Äquivalentunterscheidungsangaben in runden Klammern. In wa 39 sind dies „Kind" und „Tier". Werden Äquivalentunterscheidungsangaben angesetzt, dann werden in dem zugehörigen zweisprachigen Wörterbuchartikel im Wörterbuchgegenstandsbereich gegebene wenn-dann-Beziehungen lexikographisch vertextet (vgl. z.B. Wiegand 2009). Beispielsweise gilt für $\mathrm{wa}_{39}$ die Formulierung: Wenn großziehen (in einer seiner Formen) sich auf Kinder bezieht, dann sind vzgajati und vzgojiti (in einer entsprechenden Form) 
Wortäquivalente zu großziehen. In den Benutzungshinweisen wird dies allerdings nicht hinreichend erklärt. Die Angabenadressierungsbeziehungen in den meisten Artikeln sind leicht $\mathrm{zu}$ rekonstruieren, so dass die Informationsgewinnung für den Benutzer-in-actu ohne Schwierigkeiten möglich ist. In den meisten Artikeln ist die Adressierungskonstellation der partiell lemmatischen Adressierung gegeben; zu dieser Adressierungskonstellation gehört eine partiell lemmatisch fokussierte Adressierungsstruktur in konkreter und abstrakter Ausprägung (vgl. u.a. Wiegand 2009). Die artikelinterne konkrete partiell lemmatisch fokussierte Adressierungsstruktur, die zu wa 39 gehört, ist in Abb. 15 dargestellt.

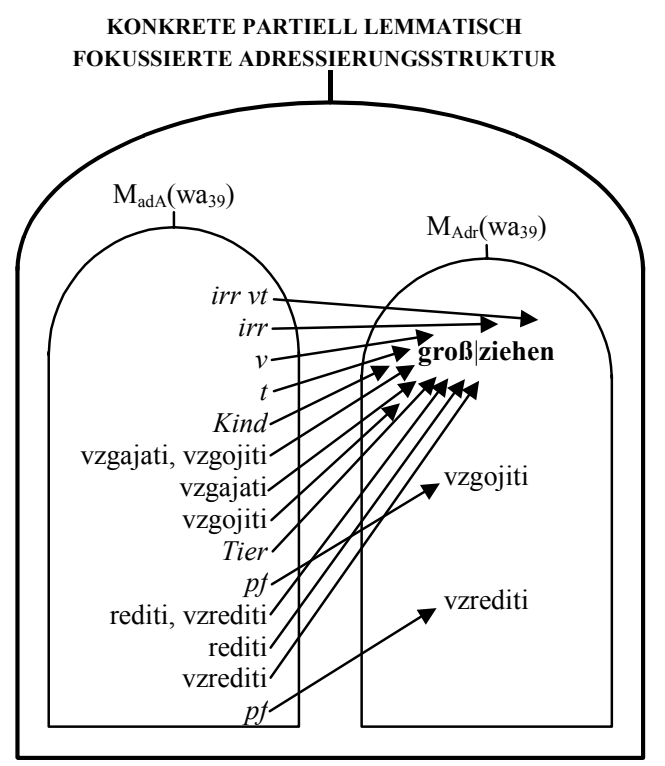

Abb. 15: Kommentiertes Pfeildiagramm zur konkreten partiell lemmatisch fokussierten Artikeladressierungsstruktur, die zu wa 39 in Abb. 13 gehört; Abkürzungen: $\mathrm{M}_{\mathrm{adA}}\left(\mathrm{wa}_{39}\right)=$ Menge $(\mathrm{M})$ der adressierten Angaben $(\operatorname{adA})$ von $\mathrm{wa}_{39} ; \mathrm{M}_{\mathrm{adr}}\left(\mathrm{wa}_{39}\right)$ $=$ Menge der Adressen (Adr) von wa 39 .

Neben der häufig auftretenden Adressierungskonstellation der partiell lemmatischen Adressierung tritt relativ selten die Adressierungskonstellation der vollständig lemmatischen Adressierung auf. Öfters ist dies in Adjektivartikeln der Fall, wenn das deutsche Adjektiv als monosem interpretiert ist, wie z.B. in wa $a_{45}$.

Ausspracheangaben werden nur bei Simplizia gegeben (vgl. z.B. wa ${ }_{41}$ und wa ${ }_{44}$ ). Das führt dazu, dass bei den Partikelverben der Benutzer nicht erfährt, dass (in Unterschied zu den Präfixverben) der Wortakzent auf dem Verbzusatz und damit auf der ersten Silbe liegt. Dies ist ein systematischer lexikographischer Fehler, der in einer nächsten Bearbeitung unbedingt beseitigt werden 
sollte und in zahlreichen neueren zweisprachigen Wörterbüchern nicht auftritt. Die einfachste Lösung ist die Hinzufügung eines freistehenden Akzentes vor den Verbzusatz als Wortakzentangabe (WAkA) z.B.:

'groß | ziehen, 'groß | schreiben, 'ab | fahren

Die präzendentive Angabestruktur einer linkserweiterten Lemmazeichengestaltangabe, mit der ein Partikelverb genannt wird, hat dann folgende Form:

WAkA $<$ VzusA $<$ AtrF $<$ StA (mit " $<"$ für geht voraus).

Will man zusätzlich die Vokalquantitätsangabe des Vokals im Verbzusatz berücksichtigen, kann man auch unten erweiternde funktionale Angabezusätze wählen, zum Beispiel einen Unterpunkt für Kürze und einen Unterstrich für Länge (großß | schreiben, ạb | fahren). Ergänzt sei, dass es für den slowenischen Benutzer auch hilfreich sein dürfte, wenn alle deutschen Lemmazeichengestaltangaben, mit denen mehrsilbige Lemmazeichen genannt werden, durch Silbentrennungsangaben in Form eines Mittenpunktes binnenerweitert wären. Die optimale Form wäre dann z.B.:

'groß $\mid$ zie•hen oder 'ab | fah•ren (oder: groß $\mid$ zie •hen, ạb $\mid$ fah•ren).

Die Angabe der Trennungsfuge wäre dann zugleich eine Silbentrennungsangabe und damit bifunktional.

Im Folgenden betrachten wir wa ${ }_{41}$, den Artikel zu grün, als Beispiel für einen mikrostrukturell reichhaltigeren Artikel. Solche Artikel weisen vor allem dt. Phrasem-, Kollokations- und Kompetenzbeispielangaben auf. Allerdings sind diese nicht als solche ausreichend identifiziert und daher für Slowenen häufig nicht unterscheidbar. Auch dies muss als ein systematischer Fehler angesehen werden. Da keine Formangaben auftreten, weist der Artikel mit dem kontinuierlichen Lemma grün keinen Kommentar zur Form und Semantik als Zweitkommentar auf, sondern einen semantischen Kommentar, dessen mikrostrukturelle Kommentarstruktur, die hierarchische rechte Kernstruktur, in abstrakter und konkreter Ausprägung in Abb. 16 und Abb. 17 dargestellt ist.

Auf den ersten Blick scheint es so, als sei die Struktur des Zweitkommentars von wa ${ }_{41}$ in Abb. 13 hochgradig komplex und ziemlich heterogen; das ist aber nicht der Fall; vielmehr ist die textuelle Struktur relativ übersichtlich. Der Zweitkommentar besteht aus zwei semantischen Subkommentaren (SSK). In beiden SSK kommt zuerst eine Angabe zur Äquivalenz (A-Äz). Mit dieser nichtelementaren Angabe werden die äquivalentrelevante Angaben genannt, die es dem Benutzer ermöglichen die semantisch-pragmatische Äquivalenz (i.S.v. Wiegand 2005b) zu erfassen, die relativ zum deutschen Lemmazeichen grün und seinen slowenischen Wortäquivalenten gegeben ist. In beiden SSK folgen auf die Angabe zur Äquivalenz Angaben von Äquivalentpaaren, die meistens binnenerweitert sind; im ersten SSK sind es sechs Angaben dieses Typs, im zweiten SSK ist es eine. Was man in den Strukturdarstellungen erken- 


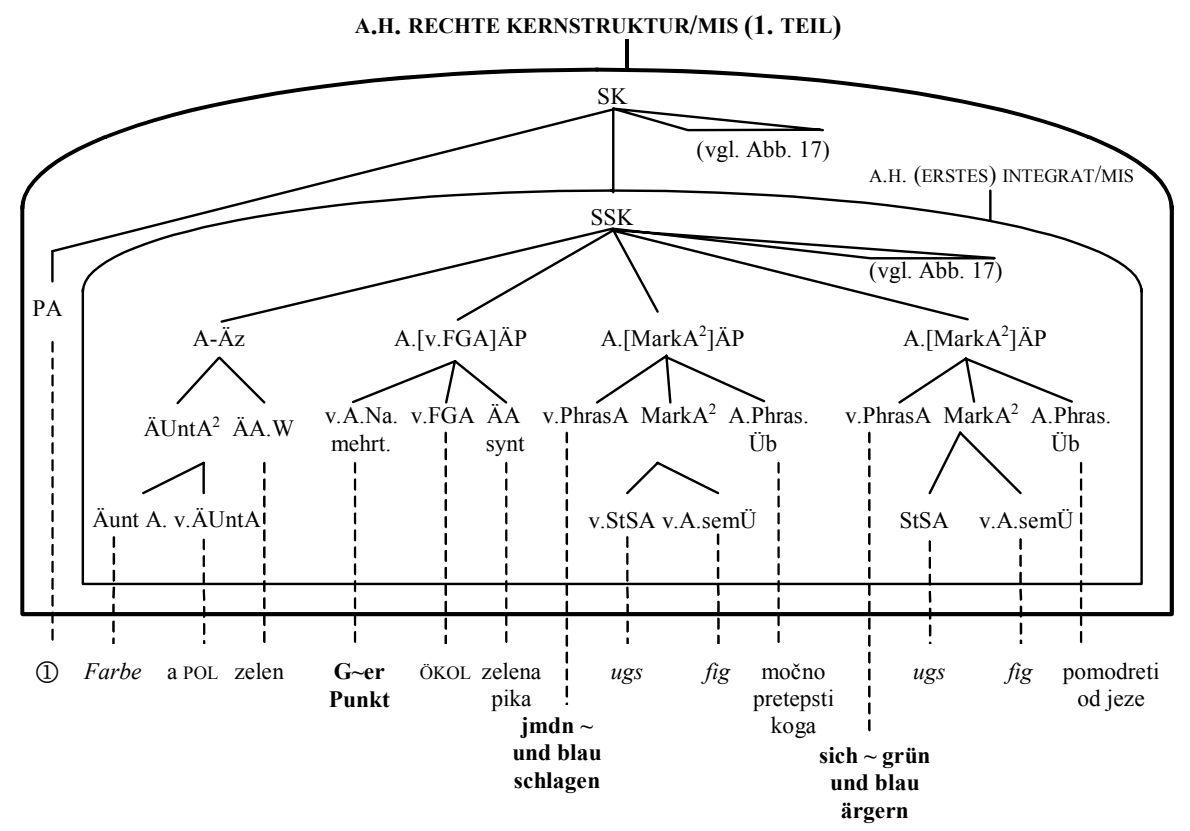

Abb. 16: Nicht vollständig ausgeführter einfach kommentierter Strukturgraph (1.Teil) zur abstrakten (und isomorphen konkreten) hierarchischen rechten Kernstruktur, die der semantische Kommentar von wa ${ }_{41}$ in Abb. 13 als Teilstruktur der Artikelmikrostrukturen aufweist; Abkürzungen: A.[v.FGA] ÄP = um eine verdichtete Fachgebietsangabe binnenerweiterte Angabe eines Äquivalentpaares; A. $\left[\right.$ MarkA $\left.{ }^{2}\right] \mathrm{ÄP}=$ um eine homosegmentäre Markierungsangabe binnenerweiterte Angabe eines Äquivalentpaares; ÄUntA² = homosegmentäre Äquivalentunterscheidungsangabe, die aus zwei ÄUntA besteht; v.A.Na.mehrt = verdichtete Angabe eines mehrteiligen Namens; v.FGA = verdichtete Fachgebietsangabe; v.PhrasA = verdichtete Phrasemangabe; v.StSA = verdichtete Stilschichtangabe; MarkA = homosegmentäre Markierungsangabe, die aus zwei Markierungsangaben besteht; v.A-semÜ = verdichtete Angabe zum semantischen Übergang; A.PhrasÜb = Angabe der Phrasemübersetzung

nen kann, nämlich von welcher Art die genannten Äquivalentpaare sind, das lässt sich anhand des Artikeltextes gerade nicht erkennen. So weiß ein slowenischer Benutzer keineswegs sicher, ob beispielsweise mit ,jmdn und blau schlagen" ein deutsches Phrasem genannt wird oder ein Kompetenzbeispiel; denn an der zugehörigen slowenischen Angabe "močno pretepsti koga“ kann er das gerade nicht erkennen, da diese eine nichtidiomatische Übersetzung ist. Hinzu kommt, dass zu viele dieser Übersetzungen schlecht oder eindeutig falsch sind, wie z.B. die mit der Angabe der Phrasemübersetzung genannte slowenische Übersetzung „(ne) doseči soglasja“, die auf Deutsch soviel wie (k)eine Zustimmung bekommen bedeutet. Die mit der verdichteten Phrasemangabe auf (k) en Zweig kommen genannten Phraseme bedeutet aber soviel wie 
(nicht, zu wenig) erfolgreich sein. Im Zweitkommentar von wa ${ }_{41}$ werden gleich zwei grundsätzliche lexikographische Fehler gemacht. Der erste besteht darin, dass Angaben, die zu unterschiedlichen Angabetypen gehören, ohne dass der jeweilige Angabetyp mit einem der üblichen Identifizierungsmethoden, nämlich typographische, nichttypographische oder positionelle Angabenidentifizierung (vgl. Wiegand 2005a: 298ff) angewandt wurden, einfach beliebig aufeinanderfolgen. Der zweite Fehler besteht darin, dass Phrasemangaben innerhalb der semantischen Subkommentare lexikographisch bearbeitet werden. Dabei spielt es keine Rolle, ob mit den Phrasemangaben teil- oder vollidiomatische Phraseme genannt werden. Denn oft genug werden vollidiomatische Phraseme aufgrund muttersprachlicher Kompetenzen fälschlich remotiviert und dann vom Lexikographen willkürlich der Bedeutung einer Phrasemkomponente zugeordnet. Das Phrasem jemandem grün und blau schlagen hat nichts mit der Bedeutung von grün (auf Farbe bezogen) zu tun; es bedeutet vielmehr einfach soviel wie jemanden gehörig verprügeln. Eine verdichtete Phrasemangabe wie z.B. jmdn und blau schlagen gehört daher nicht in den ersten semantischen Subkommentar, weil er dort im Skopus der Angaben „(Farbe [...]) zelen“ steht. Die hier anhand von wa 41 geäußerte Kritik gilt für alle Wörterbuchartikel in PonsN, in denen deutsche Phraseme lexikographisch bearbeitet sind.

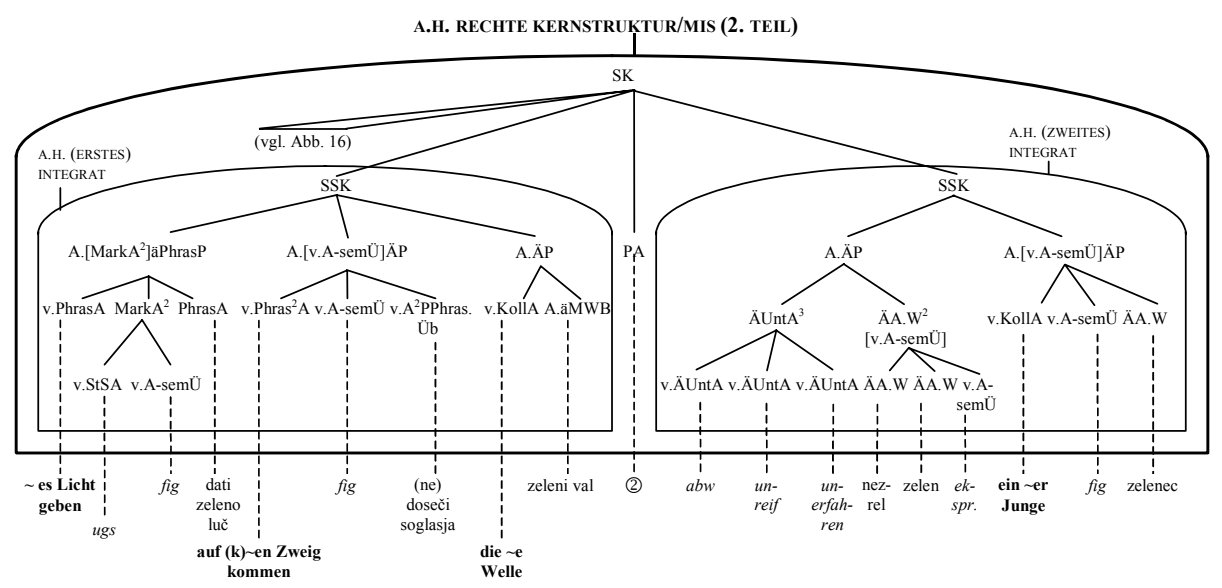

Abb. 17: Nicht vollständig ausgeführter einfach kommentierter Strukturgraph (2. Teil) zur abstrakten (und isomorphen konkreten) hierarchischen rechten Kernstruktur, die der semantische Kommentar von wa ${ }_{41}$ in Abb. 13 als Teilstruktur der Artikelmikrostruktur aufweist; Abkürzungen: A.[MarkA $\left.{ }^{2}\right]$ P̈PhasP $=$ um eine homosegmentäre Markierungsangabe binnenerweiterte Angabe eines äquivalenten Phrasempaares; A.[A-semÜ]ÄP = um eine Angabe zum semantischen Übergang binnenerweiterte Angabe eines Äquivalentpaares; v.A.PhrasÜb = verdichtete Angabe der Phrasemübersetzung; v.KollA = verdichtete Kollokationsangabe; A.äMWB = Angabe der äquivalenten Mehrwortbenennung; ÄA.W2[v.A-semÜ] = um eine verdichtete Angabe zum semantischen Übergang rechtserweiterte homosegmentäre Wortäquivalentangabe 
Es gibt verschiedene Artikeltypen (i.S.v. Wiegand 2003), die geeignet sind, um in den zugehörigen Wörterbuchartikeln die Phraseme angemessen lexikographisch zu bearbeiten. Der einfachste Artikeltyp, der dazu geeignet ist, ist der Typ des rechtserweiterten Wörterbuchartikels mit Kommentar zur Form und Semantik. Der Postkommentar ist dabei ein Postkommentar zur Phraseologie (PostK:Phras). Das einfache mikrostrukturelle Artikelstrukturschema für diesen Wörterbuchtyp lautet: WA:(Mis) FK < SK < PostK:Phras. Strukturiert man wa ${ }_{41}$ so um, dass der umstrukturierte Artikel wa' ${ }_{41}$ zu diesem Wörterbuchartikeltyp gehört und hält dabei das artikelzugehörige Datenangebot soweit konstant, dass lediglich die falsche Angabe der Phrasemübersetzung geändert und eine Phrasemidentifizierungsangabe " " hinzugefügt wird, dann ergibt sich der folgende Artikel wa' ${ }_{41}$ :
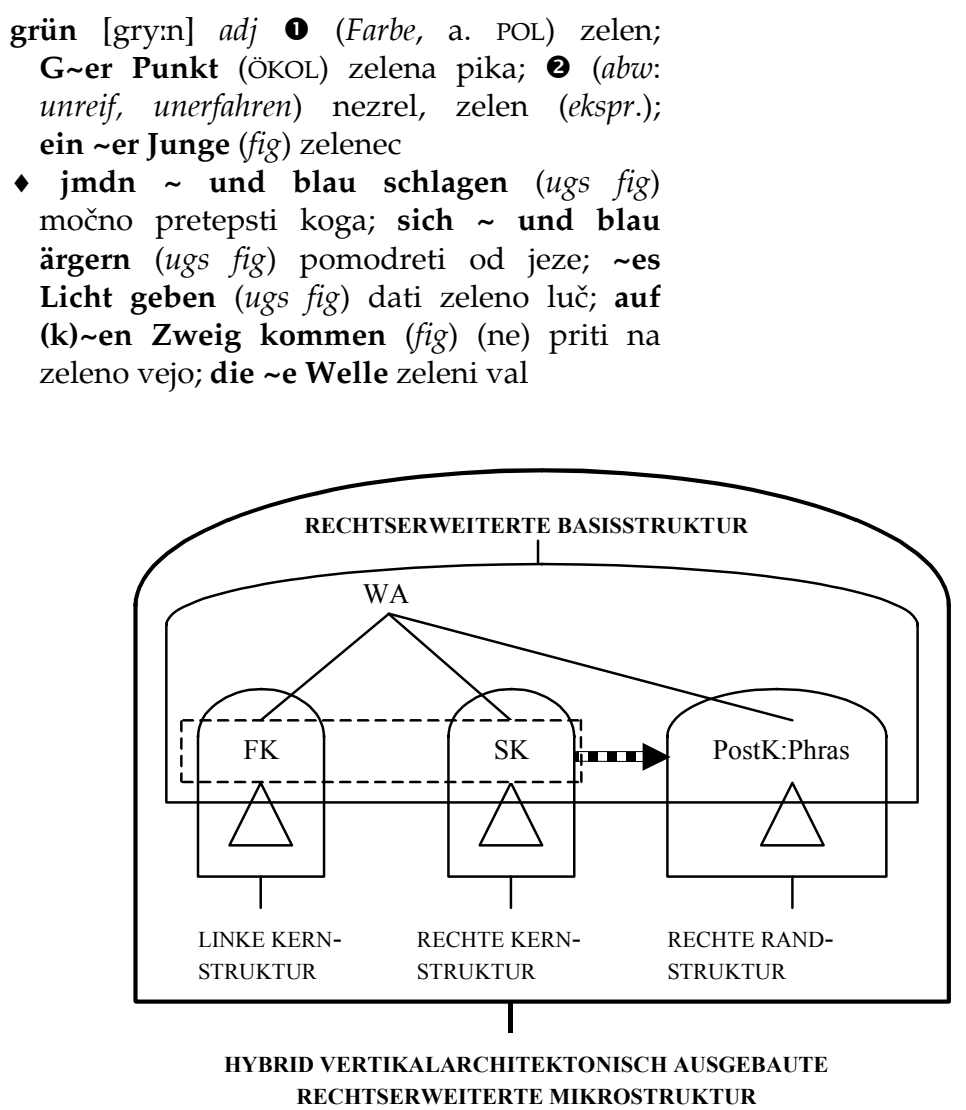

Abb. 18: Allgemeines Mikrostruktur- und Mikroarchitekturbild für hybrid vertikalarchitektonisch ausgebaute rechtserweiterte integrierte Mikrostrukturen mit als zweifach polysem interpretiertem Lemmazeichen; Abkürzungen: PostK:Phras = Postkommentar zur Phraseologie: „x $\rightarrow \mathrm{y}^{\prime \prime}$ bedeutet soviel wie $x$ ist oberhalb von $y$ 
Phrasem der Bedeutung von grün im Sinne der Farbbezeichnung zugeordnet. In wa ${ }_{47}$ ist das aber nicht der Fall, denn die Phrasemangabe steht hier nicht im ersten semantischen Subkommentar, sondern im dritten. Dieser ist aber kein regulärer semantischer Subkommentar, weil es in ihm keine Äquivalentangabe gibt, die an die Lemmazeichengestaltangabe zelèn adressiert ist. Dies bedeutet zugleich, dass "3“ in wa ${ }_{47}$ keine Polysemieangabe ist. Entsprechend werden im zuständigen Metatext von PonsS die arabischen Zahlen auch nur als Gliederungszeichen eingeführt, die den Artikel (so wie es ad hoc gerade schlecht und recht geht) irgendwie gliedern. Entsprechend könnte man den textuellen Teil, der in wa 47 auf ", 3 “ folgt als Postkommentar auffassen, so dass wa 47 ein rechtserweiterter Artikel wäre.

In anderen Artikeln wird aber wieder anders verfahren: Die Phraseme stehen dann nicht zusammen in einem Postkommentar zur Phraseologie, sondern sind auf die semantischen Subkommentare verteilt, wenn das Lemmazeichen als polysem interpretiert ist. Das bedeutet: In PonsS findet sich bei gleichartigen Eigenschaften des Wörterbuchgegenstandes eine unterschiedliche Artikelform und damit eine heterogene Strukturgebung. Dies erschwert dem Benutzer die artikelinterne Orientierung ungemein und erlaubt auch keine einheitlichen und präzisen Benutzungshinweise; entsprechend vage sind daher auch die entsprechenden Metatexte in PonsS.

Im Folgenden betrachten wird die Formkommentare von wa $\mathrm{a}_{47}$ und wa $\mathrm{a}_{50}$, also die Formkommentare von zwei Adjektivartikeln. Die Lemmazeichengestaltangabe "episkopál|en" ist durch einen senkrechten Strich binnenerweitert; mit diesem wird eine Identifizierungsangabe für das invariante Wortsegment realisiert, so dass der Benutzer erkennen kann, wo das invariante Wortsegment endet und er die Flexive anhängen muss. Identifizierungsangaben für das invariante Wortsegment dürfen nicht mit Stammidentifizierungsangaben, die sich in deutschen einsprachigen Wörterbüchern finden, verwechselt werden: Nicht jedes invariante Wortsegment ist im Slowenischen ein Stamm. In $\mathrm{wa}_{47}$ ist die Lemmazeichengestaltangabe "zelèn" nicht durch einen senkrechten Strich binnenerweitert. Das bedeutet, dass hier die Flexive an zelèn angehängt werden. Für den dt. Benutzer ist diese Angabenerweiterung, die sich auch in anderen slowenisch-deutschen Wörterbüchern findet, sehr nützlich. Hier drängt sich allerdings sofort die Frage auf, ob es für den dt. Benutzer nicht hilfreich wäre, wenn er auch im dt.-slov. Wörterbuch bei den Wortäquivalentangaben Identifizierungsangaben für das invariable Wortsegment anträfe.

Im Folgenden analysieren wir den Substantivartikel wa 48 in Abb. 19. Das erweiterte allgemeine Mikrostrukturbild von wa ${ }_{48}$ findet sich in Abb. 20.

Erweiterte allgemeine Mikrostrukturbilder sind Mikrostrukturbilder, die um Elemente der inneren Zugriffsstruktur sowie um die zugehörigen Klassen erweitert sind. Sie optimieren die Übersicht über die Artikelmikrostruktur; im vorliegenden Fall zeigen sie, dass die inneren Zugriffstextelemente keine Polysemieangaben sind, sondern nichttypographische Mikrostrukturanzeiger vom Typ der Trennzeichen. - In Abb. 21 wird im Folgenden die reine mikrostruk- 
turelle Kommentarstruktur des Formkommentars, also die linke Kernstruktur als Teilstruktur der reinen Artikelmikrostruktur, dargestellt.

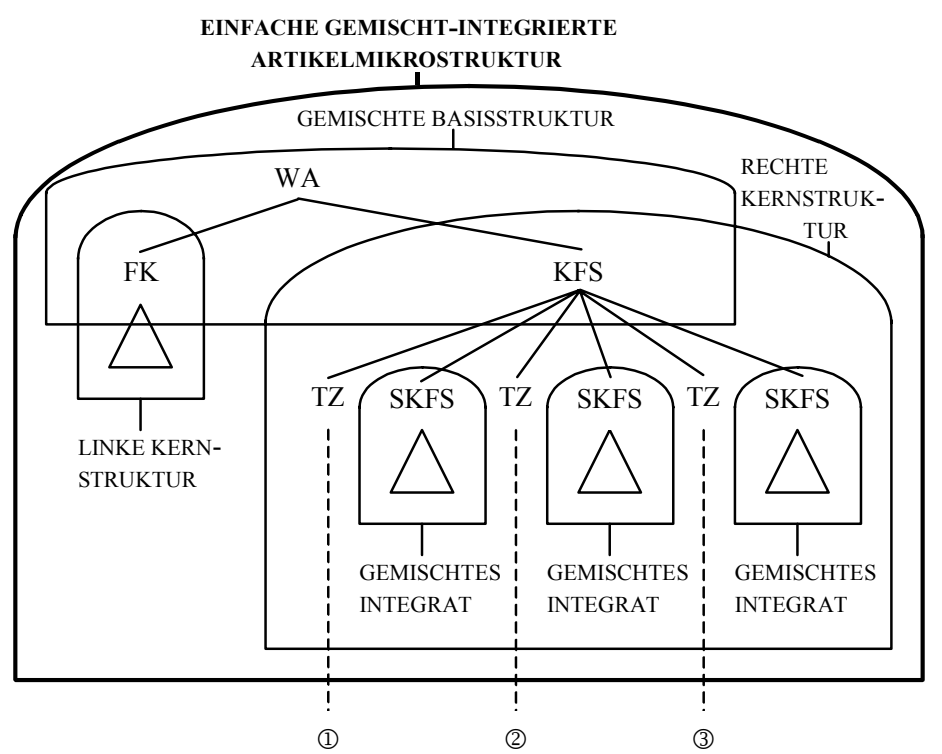

Abb. 20: Erweitertes allgemeines Mikrostrukturbild zu wa48 und allen PonS-Artikeln mit isomorpher Artikelmikrostruktur; Abkürzungen: TZ = Trennzeichen; Darstellungskonvention: " $\mathrm{x}---\mathrm{Y}^{\prime \prime}=\mathrm{x}$ ist ein Element von $\mathrm{Y}(\mathrm{x} \in \mathrm{Y})$ (von unten nach oben gelesen)

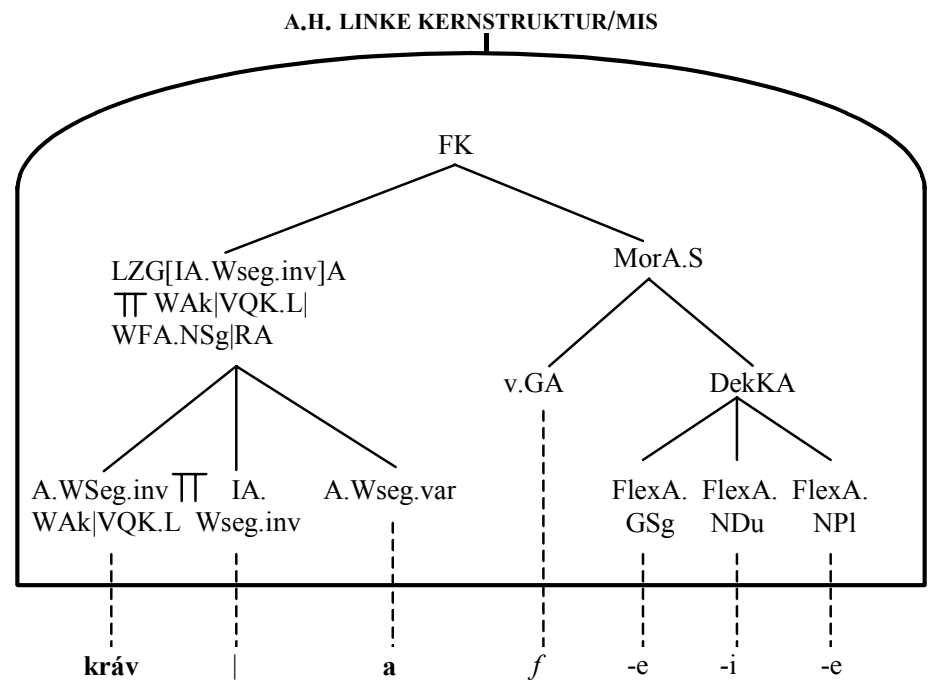

Abb. 21: Einfach kommentierter Strukturgraph zur abstrakten (und isomorphen konkreten) hierarchischen Kernstruktur als Teilstruktur der reinen Artikelmikro- 
struktur, die der Formkommentar von wa ${ }_{48}$ in Abb. 19 aufweist; Abkürzungen: IA.W.Seg.inv = Identifizierungsangabe für das invariante Wortsegment; A.Wseg.inv = Angabe des invarianten Wortsegments; A.Wseg.var = Angabe des variablen Wortsegments; LZG[IA.Wseg.inv]A = Lemmazeichengestaltangabe, binnenerweitert um eine Identifizierungsangabe für das invariante Wortsegment; FlexA.NDu = Flexivangabe. Nominativ Dual

Die abstrakte hierarchische linke Kernstruktur in Abb. 21 ist zu Hunderten von konkreten linken Kernstrukturen in PonsS isomorph. Die gesamten Formkommentare im PonsS sind bei gleichen Formeigenschaften strukturell gleichwertig gestaltet. Bei gleichem Lemmazeichentyp sind entsprechend die linken Kernstrukturen isomorph. Entsprechendes gilt nicht für die Kommentare zur Form und Semantik. Sie sind strukturell, ohne dass der jeweilige Wörterbuchgegenstand dies erzwingt, ausgesprochen heterogen und die sprachlichen Fehler beim Wörterbuchgegenstand sind zahlreich.

Im Folgenden analysieren wir den Kommentar zur Form und Semantik von wa ${ }_{48}$ in Abb. 19 hinsichtlich der Artikelform und hinsichtlich des Artikelgegenstands. In Abb. 22 findet sich die Darstellung der abstrakten (und isomorphen konkreten) hierarchischen rechten Kernstruktur, die der Kommentar zur Form und Semantik von wa 48 in Abb. 19 aufweist.

Im Folgenden betrachten wir die lexikographische Bearbeitung des Artikelgegenstands in den drei Subkommentaren zur Form und Semantik (SKFS). Im ersten SKFS ist mit „Kuh“ der zoologische Ausdruck für weibliche Tiere gemeint, so wie er z.B. in "Seekuh" als Zweitkonstituente, aber auch z.B. in Hirschkuh, Elefantenkuh u.a. vorkommt. Diese Kühe werden aber nicht gemolken! Daher passt die Angabe eines äquivalenten Kollokationspaares „molsti e Kühe melken" nicht in den ersten SKFS. Im zweiten SKFS ist "Melkkuh" veraltet, da es von dem veralteten intransitiven Verb melken i.S. von Milch geben abgeleitet ist. Das Phrasem: „wo haben wir denn schon zusammen Schweine gehütet?" kommt im Deutschen selten vor. Die innere Selektion im zweiten SKFS ist daher zumindest äußerst ungeschickt. Das frequenteste Äquivalent, nämlich das alltägliche verwendete Wort Kuh (mit dem das weibliche Hausrind nach dem ersten Kalben bezeichnet wird), erscheint erst im dritten SKFS; „,mol$\mathbf{s t i} \sim \mathbf{e}^{\prime \prime}$ gehört dann in den dritten SKFS. Die innere Selektion ist ein Thema für sich und kann hier nicht angemessen behandelt werden. Es sei nur auf das Folgende aufmerksam gemacht. Zahlreiche dt. Komposita mit innerer Idiomatisierung, wie z.B. Kuhhandel, die in PonsN als Lemma angesetzt sind und eine slowenische Mehrwortbenennung als Äquivalent aufweisen, wie z.B. kravja kupčija, haben keine Chance im PonsS als Äquivalent zu erscheinen, weil die entsprechende Mehrwortbenennung in dem entsprechenden Adjektivartikel in PonsS nicht gebucht ist. So findet sich in wa ${ }_{51}$ nur ", e mleko Kuhmilch f" und " $\sim \mathbf{i}$ zvonec Kuhglocke f“'; es fehlen u.a. kravja kupčija und kravja koža.

Insgesamt kann festgestellt werden, dass sich positive und negative Aspekte in PonsN und PonsS in etwa die Waage halten. Für gehobene Ansprüche sind beide Wörterbücher ungeeignet. Solange die lexikographische Bearbeitung 


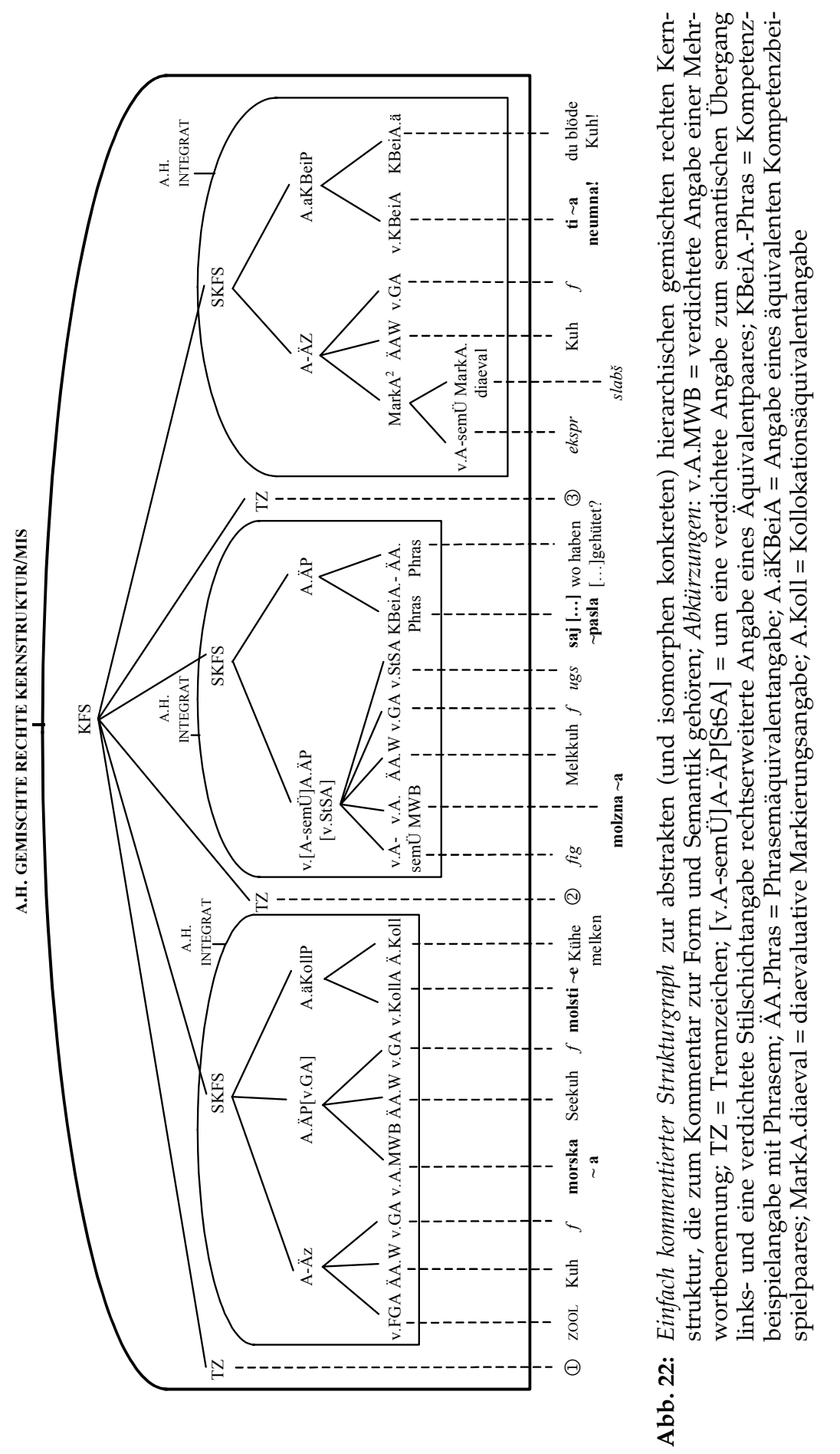


innerhalb der Wörterbuchartikel nur im Rahmen von basalen Wörterbuchartikeln mit einfachen integrierten und einfach gemischt-integrierten Mikrostrukturen erfolgt, ist hier kein Fortschritt zu erwarten. Denn falls man solche Wörterbuchartikel mit zusätzlichen Daten anreichert, werden die Artikel des genannten Typs unübersichtlich. Für ein anspruchsvolles zweisprachiges Großwörterbuch sind sie nicht geeignet. Auch das gerade erschienene PonsN/SKompWb ist keine wirkliche Weiterentwicklung, sondern fasst in den Wörterverzeichnissen im Wesentlichen PonsN und PonsS zu einem Band zusammen.

\subsection{DebN und DebS}

Wir betrachten zunächst DebN. Nach dem Titel gehört DebN zu den Großwörterbüchern; nach eigenen Angaben weist es ca. 120500 Lemmata auf. Die monoalphabetische Makrostruktur ist glattalphabetisch und mit der Hauptzugriffsstruktur identisch. Jeder Wörterbuchartikel beginnt mit einer neuen Zeile. DebN ist mithin ausgesprochen zugriffsfreundlich. Ca. 90\% aller Wörterbuchartikel sind Kurzartikel: Sie sind nicht länger als zwei Spaltenzeilen. Ca. 90\% der Kurzartikel sind Einzeilenartikel. Ein für DebN typischer Artikelstreckenausschnitt findet sich in (1) in Abb. 23.

(1)

Sammelfrucht, die, $\bullet$ birni plod
Sammelgebiet, das, zbirateljsko področje, področje,
s katerega kdo zbira
Sammelgefäß, das, zbirna/zbiralna posoda
Sammelglas, das, zbiralna leča, konkavna leča
Sammelgrab, das, skupinski grob
Sammelgut, das, zbirno blago
Sammelhefter, der, T stroj za vezavo revij
Sammelheizung, die, T centralno ogrevanje
Sammelkasse, die, osrednja blagajna
Sammelkasten, der, T zbiralna posoda
Sammelkatalog, der, zbirni katalog
Sammelkonto, das, zbirni račun
Sammelladung, die, 2 zbirna pošiljka
Sammellager, das, zbirno skladišce
Sammelleidenschaft, die, zbiralska strast
Sammelleitung, die, zbiralni vod, zbirni vod, kolek-
tor
Sammellinse, die, zbiralna leča, konveksna leča
Sammelliste, die, zbiralni seznam, seznam daroval-
cev
Sammelmappe, die, zbiralna mapa
Sammelmulde, die, T zbiralna posoda
sammeln (sich se) zbirati, zbrati; Pilze, Holz usw.:
nabirati; Erfahrungen: pridobivati; Reichtümer:
kopičiti; all seine Kräfte zbrati vse moči; seine
Gedanken zbrati se

Wa73:

Glühbirne, die, žarnica

Wa74:

vrč $M(-\mathrm{a} . .$.$) der Krug (s pokrovom Deckelkrug, za vino Wein-$ $\mathrm{krug}, z a$ vodo Wasserkrug, $z$ ročajem Henkelkrug), die Kanne (za vodo Wasserkanne, locnat Bügelkanne, $z$ ročem Henkelkanne); $\mathbf{v} \sim$ ih/cele $\sim$ e krugweise; FIG. hodi po vodo, dokler se ne razbije der Krug geht so lange zum Brunnen, bis er bricht

wa75:

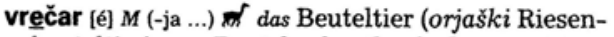
beuteltier); ... Beutel-, -beutler; jazbec $\sim$ der Beuteldachs; krt der Wühlbeutler, der Beutelmull; mali leteči der Zwergflugbeutler; veliki leteči der Riesenflugbeutler; medvedek (koala) der Koala; mravojedi $\sim$ der Ameisenbeutler; obročastorepi plezalec der Ringschwanz-Kletterbeutler; perorepi der Federschwanzbeutler; plezalec der Kletterbeutler; polh der Schlafmausbeutler; progasti veveričji der Streifenkletterbeutler; rilčasti der Rüsselbeutler; skakač der Springbeutler; $\sim$ svinjenožec der Stutzbeutler; volk $\sim$ der Beutelwolf; zverski der Raubbeutler

Abb. 23: Artikelteilstrecke (1) (= wa $\left.a_{52}-w^{2} a_{72}\right)$ und Wörterbuchartikel wa $a_{73}$ aus DebN; wa74 und wa75 aus DebS 
In DebN sind 65 Komposita mit der Erstkonstituente „Sammel-" gebucht. Im zehnbändigen Duden- ${ }^{3} \mathrm{GW}$, dem größten Wörterbuch des gegenwärtigen Deutsch, sind es 58; in PonsN sind es neun. Bei anderen überprüften Komposita sind die Zahlen ähnlich. Dies zeigt, dass DebN zu den zweisprachigen Wörterbüchern mit reichhaltiger Makrostruktur gehört. Das Datenangebot in den Wörterbuchartikeln ist dagegen ausgesprochen armselig; weder die slowenischen noch die deutschen Benutzer können damit zufrieden sein. In den Artikeln, in denen es etwas reichhaltiger ist, ist öfters die textuelle Strukturierung wenig klar. Zu den Kurzartikeln ist unter der Voraussetzung, dass es für das Sprachenpaar Deutsch/Slowenisch nur ein Großwörterbuch für dt. und slow. Benutzer geben kann, zunächst festzuhalten, dass das ein solches Wörterbuch polyfunktional sein muss. Unter dieser Voraussetzung sind sämtliche Kurzartikel sowohl in DebN als auch in DebS eine Zumutung für den Benutzer. Am Beispiel von wa73 in Abb. 23 sei dies erläutert. Will ein slow. Benutzer wissen, wie Glühbirne dekliniert wird, muss er unter Birne nachschlagen, und will er wissen wie Glühbirne getrennt und ausgesprochen wird, erfährt er in DebN nichts. Will der dt. Benutzer wissen, wie Glühbirne im Slowenischen heißt, bekommt er eine halbe Antwort ohne morphologische Angaben. Ein brauchbarer Kurzartikel, der einem slow. und dt. Benutzer weiteres Nachschlagen erspart, kann z.B. die folgende Form aufweisen:

wa'73: Glüh|bir·ne ['gly:birnə], die <-, -n> žárnic|a $f<-\mathrm{e},-\mathrm{i},-\mathrm{e}>$

DebN ist erst dann bei den Substantivartikeln ein brauchbares Großwörterbuch von mittlerem Wert, wenn das in wa' 73 realisierte Minimalprogramm erfüllt ist. Das Wörterbuch kann zu einem guten Großwörterbuch weiterentwickelt werden, wenn die deutsche Deklinationsklassenangabe $<-,-n>$ durch eine numerische verweisvermittelnde Deklinationsmusterangabe angereichert wird (z.B $<-;-n ; 26>$, denn bekanntlich reicht die Deklinationsklassenangabe für viele Nichtmuttersprachler nicht aus, um alle Substantivformen bilden zu können; "26" verweist auf einen tabellarischen Umtext mit Deklinationstabellen. $\mathrm{Zu}$ einer angemessenen Weiterentwicklung gehört weiter, dass wichtige Kollokationen und entsprechende Äquivalente genannt werden und im Postkommentar die wichtigsten Phraseme, in denen das Lemmazeichen als Phrasemkomponente auftritt. Soll ein wirklich sehr gutes Wörterbuch entstehen, müssen sehr viel mehr Lemmazeichen als polysem interpretiert werden und in den semantischen Subkommentaren müssen textuelle Synonym- und Antonympositionen vorgesehen werden. Nach DebN sind deutlich über $90 \%$ der deutschen Lemmazeichen als monosem interpretiert: Von den sprachlichen Gegebenheiten im Wörterbuchgegenstandsbereich, also bei der lexikographischen Ausgangssprache und ihrem Gebrauch, ist eine solche lexikographische Darstellung meilenweit entfernt.

Die Verbartikel sind in der Regel mikrostrukturell reichhaltiger als die Substantivartikel, aber auch sie weisen systematische Mängel auf. Wir nennen nur einige: Die Partikelverben sind von den Präfixverben nicht dadurch unterschieden, dass die Trennungsfuge markiert ist. Das Hilfsverb zur Bildung der 
zusammengesetzten Tempusformen (sein vs hat) wird nicht genannt. Weder die syntaktische Verbklasse (transitiv vs intransitiv) bei der lexikographischen Ausgangssprache wird angegeben, noch ist eine Angabe der semantischen Verbklasse (perfektiv vs imperfektiv) an die Verbäquivalentangabe adressiert. In diesen Hinsichten sind die Verbartikel in PonsN erheblich angemessener gestaltet. Ein schwieriges Problem bilden für Nichtmuttersprachler die korrekten deutschen Anschlusspräpositionen. Diese sind vom Verb regiert und müssen angegeben werden; nur selten ist das der Fall. — Eine lexikographische Unsitte ist es auch, den Lemmabestand dadurch zu vermehren, dass substantivierte Verben als Lemmata angesetzt werden, z.B. „Bewegen, das"; „Tränken, das"; "Tränen, das" und „Tragen, das". Auch wenn dieser Lemmasatz z.T. dadurch bedingt sein kann, dass besondere slowenische Äquivalente gegeben sind, gehören die substantivierten Infinitive in die Verbartikel.

Bei den Adjektivartikeln fehlen häufig die Angaben der graduierten Formen, wenn der Stammvokal umgelautet wird (vgl. z.B. s.v. groß, kurz, lang1). Bei anderen Adjektiven sind die Angaben falsch, vgl. z.B. s.v. hoch. Hier findet man im Formkommentar "hoher, hohe, hohes"! Korrekt wäre: höher, höchste. Selbst die Suppletivformen bei gut fehlen. Zwar ist besser als Lemma angesetzt, erhält aber als verdichtete Wortartangabe „ADV." (= Adverb), und auf diese verdichtete Wortangabe folgt die Beispielangabe " $\sim$ e Tage"! Neben den genanten systematischen Defiziten in den Substantiv-, Verb- und Adjektivartikeln finden sich in DebN zahlreiche sprachliche Fehler. Wir wollen es bei dieser Feststellung belassen.

Verglichen mit den bisher in Plet, PonsN und PonsS behandelten treten in DebN keine andersartigen Typen von Artikelmikrostrukturen auf, so dass sich Strukturdarstellungen erübrigen.

Abschließend betrachten wir DebS und beginnen mit dem Artikel wa ${ }_{74}$ in Abb. 23. Die abstrakte (und isomorphe konkrete) hierarchische einfache gemischt-integrierte Artikelmikrostruktur ist in Abb. 24 dargestellt.

Wie Abb. 24 zeigt, weist wa 74 keine Subkommentare zur Form und Semantik auf, da die Polysemieangaben fehlen, obwohl das Substantiv vrč, wie die beiden nichtsynonymen Äquivalentangaben "Krug" und „Kanne“ zeigen, als zweifach polysem interpretiert ist. In anderen vergleichbaren Artikeln treten aber Polysemieangaben auf. Weiterhin ist es wenig sinnvoll, an Sprichwortangaben die verdichtete Markierungsangabe „FIG“ zu adressieren. Besser wäre eine Sprichwortidentifizierungsangabe, z.B. SPW.

Sehr oft sind die längeren Wörterbuchartikel in DebS — wie wa ${ }_{74}$ — nicht übersichtlich gegliedert. Daher gibt es in den Benutzungshinweisen keine brauchbaren Hinweise zu Artikelgliederung. In zahlreichen Substantivartikeln - wie z.B. wa75 in Abb. 23 - mit dem Lemma vrečar, die entweder mit dem Symbol für Tierkunde oder dem für Pflanzenkunde versehen sind, dessen Skopus - wie in wa 7 $_{4}$ - häufig der gesamte Kommentar zur Form und Semantik ist, werden slowenische Mehrwortbenennungen und zugehörige deutsche Komposita genannt, die in einem allgemeinen zweisprachigen Wörterbuch nichts zu suchen haben. Sie gehören vielmehr in entsprechende Fachwörterbücher. 

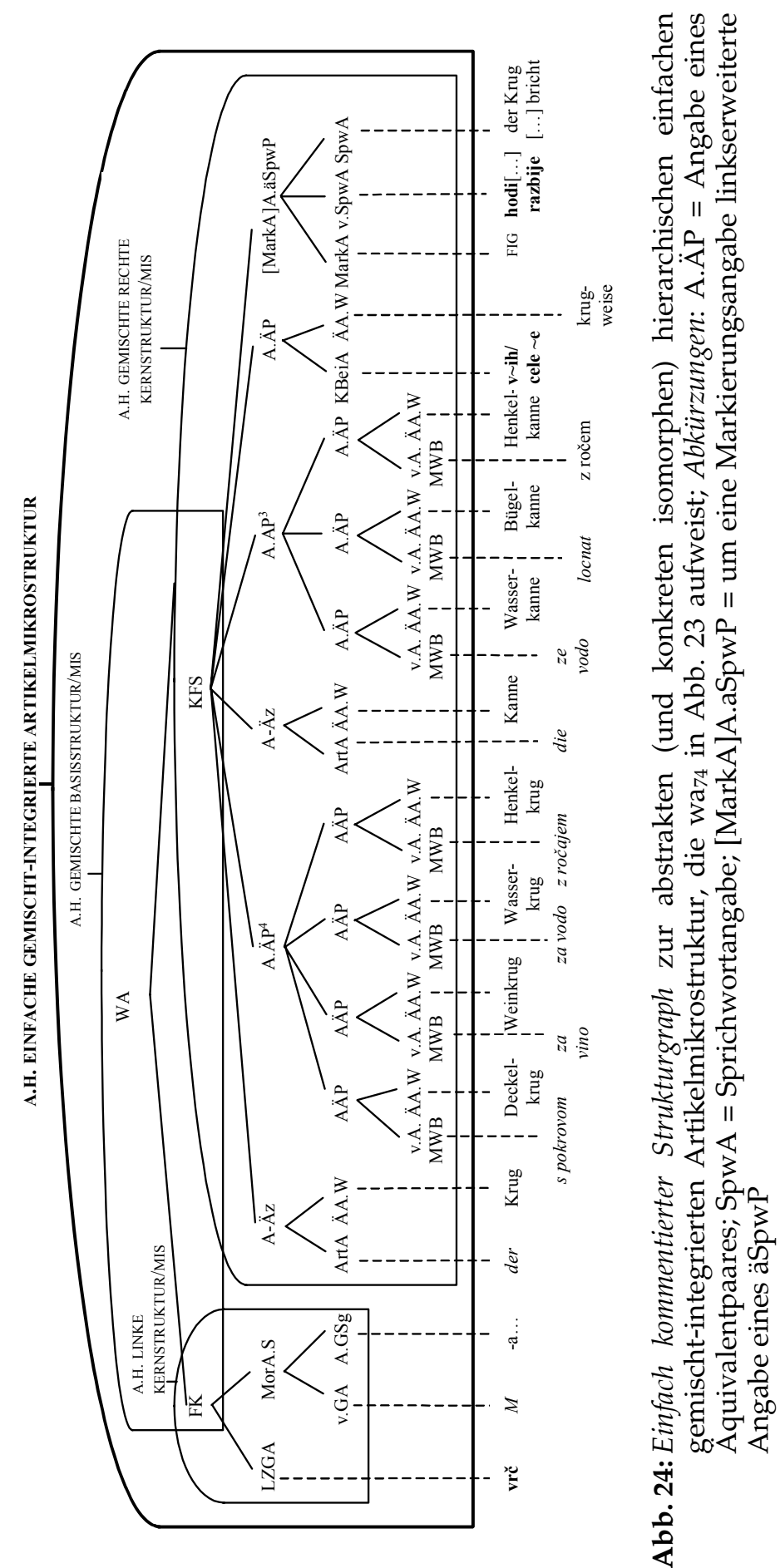
Zusammenfassend muss gesagt werden, dass DebN und DebS den Anforderungen, die an ein modernes allgemeines zweisprachiges Großwörterbuch gestellt werden, nur hinsichtlich des Umfangs des Lemmabestandes genügen. Die textuellen Strukturen der Wörterbuchartikel und das Datenangebot in diesen genügen diesen Anforderungen nicht.

\section{Schlussbemerkung}

Zum Stand der allgemeinsprachlichen Lexikographie im Sprachenpaar Deutsch und Slowenisch kann abschließend festgestellt werden: Die lexikographische Versorgung ist für relativ anspruchslose Nachschlagebedürfnisse sichergestellt. Für jede Form von Wörterbuchbenutzung, die in Zusammenhang mit der Produktion, Rezeption und Übersetzung von anspruchsvolleren allgemeinsprachlichen Texten steht, ist die lexikographische Versorgung nur sehr eingeschränkt sichergestellt. Wie sich diese unbefriedigende Lage schrittweise verbessern lässt, wurde für die untersuchten Wörterbücher u.a. dadurch gezeigt, dass hierzu jeweils ein Minimalprogramm für angemessener Wörterbuchartikel und ihre Vernetzung mit akzessiven Umtexten genannt wurde, so dass bestimmte realistische Perspektiven zu einer Verbesserung der lexikographischen Versorgung sichtbar werden.

Eine grundlegende Verbesserung der lexikographischen Versorgung im Sprachenpaar Deutsch und Slowenisch ist aber nur möglich, wenn ein neues modernes bidirektionales und polyfunktionales Großwörterbuch mit modernen Methoden erarbeitet wird, in dem das Wissenskorpus der modernen Wörterbuchforschung genutzt wird, so dass die in der Praxis auftretenden grundsätzlichen Fehler nicht stets auf Neue reproduziert werden.

\section{Literatur}

DebN = Debenjak, Doris, Božidar Debenjak und Primož Debenjak (Hrsg.). 2003. Veliki nemškoslovenski slovar. 2. Aufl. Ljubljana: DZS.

DebS = Debenjak, Doris, Božidar Debenjak und Primož Debenjak (Hrsg.). 2003. Veliki slovenskonemški slovar. 2. Aufl. Ljubljana: DZS.

Duden-3 GW = Wissenschaftlicher Rat der Dudenredaktion. 1999. Duden. Das große Wörterbuch der deutschen Sprache in zehn Bänden. 3., völlig neu bearb. u. erw. Aufl. Mannheim [usw.]: Dudenverlag.

Furlan, Metka. 2006. O Pleteršnikovem slovarju skozi čas. K transliterirani izdaji Pleteršnikovega slovarja. Pleteršnik, Maks und Metka Furlan (Hrsg.). 2006. Slovensko-nemški slovar (18941895). Bd. 2, I-XV. Transliterierte Ausg. Ljubljana: Založba ZRC SAZU.

Furlan, Metka. 2008. Ob izidu nove izdaje Pleteršnikovega Slovensko-nemškega slovarja. Jesenšek, Marko (Hrsg.). Od Megiserja do elektronske izdaje Pleteršnikovega slovarja. 2008: 363-367. Maribor: Filozofska fakulteta, Oddelek za slovanske jezike in književnosti.

Hausmann, Franz Josef, Oskar Reichmann, Herbert Ernst Wiegand und Ladislav Zgusta (Hrsg.). 1989-1991. Wörterbücher. Ein internationales Handbuch zur Lexikographie/Dictionaries. An Inter- 
national Encyclopedia of Lexicography/Dictionnaires. Encyclopédie internationale de lexicographie. Handbücher zur Sprach- und Kommunikationswissenschaft. 3 Teilbände. Berlin/New York: Walter de Gruyter.

Hausmann, Franz-Josef und Herbert Ernst Wiegand. 1989. Component Parts and Structures of General Monolingual Dictionaries: A Survey. Hausmann, F.J., O. Reichmann, H.E. Wiegand und L. Zgusta (Hrsg.). 1989-1991: 328-360.

Jakopin, Franc. 1994. Maks Pleteršnik — mojster slovenskega slovaropisja. Ob stoletnici izhajanja njegovega slovensko-nemškega slovarja. Orožen, Martina (Hrsg.). 1994. XXX. seminar slovenskega jezika, literature in kulture: 23-34. Ljubljana: Seminar slovenskega jezika, literature in kulture pri Oddelku za slovanske jezike in književnosti Filozofske fakultete.

Jakopin, Franc. 1997. Pleteršnikovo mesto v sočasnem slovaropisju. Novak, France (Hrsg.). 1997. Maks Pleteršnik: 9-15. Ljubljana: Zavod Republike Slovenije za šolstvo.

Jesenšek, Vida. 2004. Frazeologija v Pleteršnikovem slovensko-nemškem slovarju: jezikovnosistemska in prevodna ustreznost. Jesenšek, Marko (Hrsg.). 2004. Besedoslovne lastnosti slovenskega jezika: slovenska zemljepisna imena: 241-252. Ljubljana: Slavistično društvo Slovenije/ Pišece: Društvo Pleteršnikova domačija.

Jesenšek, Vida. 2005. Frazeologija v splošnih dvojezičnih slovarjih: razmislek ob nemško-slovenskih slovarjih avtorjev Debenjak. Jesenšek, Marko (Hrsg.). 2005. Knjižno in narečno besedoslovje slovenskega jezika: 154-172. Maribor: Slavistično društvo.

Kammerer, Matthias und Herbert Ernst Wiegand. 1998/99. Über die textuelle Rahmenstruktur von Printwörterbüchern. Präzisierungen und weiterführende Überlegungen. Lexicographica 14: 224-238.

Konerding, Klaus-Peter und Herbert Ernst Wiegand. 1994. Framebasierte Wörterbuchartikel. Zur Systematisierung der lexikographischen Präsentation des Bedeutungswissens zu Substantiven. Lexicographica 10: 100-170.

Meyer, Meike und Herbert Ernst Wiegand. 2000. Gemischt-semiintegrierte Mikrostrukturen für deutsch-spanische Printwörterbücher. Wiegand, Herbert Ernst (Hrsg.). 2000. Studien zur zweisprachigen Lexikographie mit Deutsch V: 87-171. Germanistische Linguistik 151-152. Hildesheim/New York: Georg Olms Verlag.

Pan Zaiping und Herbert Ernst Wiegand. 1995. Über die Musterartikel für das große DeutschChinesische Wörterbuch. Zugleich ein Beitrag zu einer Theorie zweisprachiger lexikographischer Texte. Wiegand, Herbert Ernst (Hrsg.). 1995. Studien zur zweisprachigen Lexikographie mit Deutsch II. Germanistische Linguistik 127-128. Hildesheim/Zürich/New York: Georg Olms Verlag.

Plet $=$ Pleteršnik, Maks und Metka Furlan (Hrsg.). 2006. Slovensko-nemški slovar (1894-1895). Transliterierte Ausg. Ljubljana: Založba ZRC SAZU.

PonsN = Jemec Škoda, Marjeta et al. (Hrsg.). 2006. Splošni nemško-slovenski slovar. Ljubljana: Rokus. PonsS = Martinčič, Polona et al. (Hrsg.). 2008. Splošni slovensko-nemški slovar. 1. Aufl. Ljubljana: Rokus.

PonsN/S-KompWb = Kompaktwörterbuch Slowenisch. Slowenisch-Deutsch/Deutsch-Slowenisch. 2009. Neubearb. Stuttgart: Klett.

Schierholz, Stefan und Herbert Ernst Wiegand. 2005. Die Wörterbücher zur Sprach- und Kommunikationswissenschaft. Eine neue Konzeption der linguistischen Fachlexikographie und ihre computergestützte Praxis. Lexicographica 20: 164-264. 
Toporišič, Jože. 1998. Pleteršnikov pravopis v Slovensko-nemškem slovarju. Toporišič, Jože (Hrsg.). Pleteršnikov slovensko-nemški slovar. Zbornik s simpozija '96 v Pišecah: 5-15. Novo mesto: Dolenjska založba.

Wahrig-8DW = Wahrig-Burfeind, Renate (Hrsg.). 2006. Deutsches Wörterbuch. Mit einem Lexikon der Sprachlehre. 8. vollst. neu bearb. Aufl. Gütersloh/München: Wissen Media Verlag GmbH.

Wiegand, Herbert Ernst. 1989. Aspekte der Makrostruktur im allgemeinen einsprachigen Wörterbuch: Alphabetische Anordnungsformen und ihre Probleme. Hausmann, F.J., O. Reichmann, H.E. Wiegand und L. Zgusta (Hrsg.). 1989-1991: 246-280.

Wiegand, Herbert Ernst. 1989a. Der Begriff der Mikrostruktur. Geschichte, Probleme, Perspektiven. Hausmann, F.J., O. Reichmann, H.E. Wiegand und L. Zgusta (Hrsg.). 1989-1991: 409-462.

Wiegand, Herbert Ernst. 1989b. Arten von Mikrostrukturen im allgemeinen einsprachigen Wörterbuch. Hausmann, F.J., O. Reichmann, H.E. Wiegand und L. Zgusta (Hrsg.). 1989-1991: 462-501.

Wiegand, Herbert Ernst. 1990. Printed Dictionaries and their Parts as Texts. An Overview on Recent Research as Introduction. Lexicographica 6: 1-126. [Auch in Wiegand 2000: 951-1062.]

Wiegand, Herbert Ernst. 1990a. Die deutsche Lexikographie der Gegenwart. Hausmann, F.J., O. Reichmann, H.E. Wiegand und L. Zgusta (Hrsg.). 1989-1991: 2100-2246.

Wiegand, Herbert Ernst. 1991. Über die Strukturen der Artikeltexte im Frühneuhochdeutschen Wörterbuch. Zugleich ein Versuch zur Weiterentwicklung einer Theorie lexikographischer Texte. Goebel, Ulrich und Oscar Reichmann (Hrsg.). 1991. Historical Lexicography of the German Language. Volume 2: 361-673. Studies in Russian and German 3. Lewiston/Queenston/Lampeter: Edwin Mellen Press.

Wiegand, Herbert Ernst. 1995. Lexikographische Texte in einsprachigen Lernerwörterbüchern. Kritische Überlegungen anlässlich des Erscheinens von Langenscheidts Großwörterbuch Deutsch als Fremdsprache. Popp, Heidrun (Hrsg.). 1995. Deutsch als Fremdsprache. An den Quellen eines Faches. Festschrift für Gerhard Helbig zum 65. Geburtstag: 463-499. München: Judicium Verlag.

Wiegand, Herbert Ernst. 1995a. Deutsch-Türkmenisches Wörterbuch. Einblicke in die Wörterbucharbeit an der Türkmenischen Staatlichen Magtymguly-Universität in Aschghabat. Lexicographica 10: 249-300.

Wiegand, Herbert Ernst. 1996. Das Konzept der semiintegrierten Mikrostrukturen. Ein Beitrag zur Theorie zweisprachiger Printwörterbücher. Wiegand, Herbert Ernst (Hrsg.). 1996. Wörterbücher in der Diskussion II. Vorträge aus dem Heidelberger Lexikographischen Kolloquium: 1-82. Lexicographica. Series Maior 70. Tübingen: Max Niemeyer Verlag. [Auch in Wiegand 2000: 1193-1277.]

Wiegand, Herbert Ernst. 1996a. Deutsch-Usbekisches Wörterbuch. Einblicke in die Wörterbucharbeit an der Staatlichen Usbekischen Weltsprachen-Universität in Taschkent. Lexicographica 12: 190-254. [Auch in Wiegand 2000: 1339-1409.]

Wiegand, Herbert Ernst. 1996b. Über die Mediostrukturen bei gedruckten Wörterbüchern. Zettersten, Arne und Viggo Hjørnager Pedersen (Hrsg.). 1996. Symposium on Lexicography VII. Proceedings of the Seventh Symposium on Lexicography May 5-6, 1994 at the University of Copenhagen: 11-43. Lexicographica. Series Maior 76. Tübingen: Max Niemeyer Verlag. [Auch in Wiegand 2000: 1163-1192.]

Wiegand, Herbert Ernst. 1997. Printed Language Dictionaries and their Standardization: Notes on the Progress toward a General Theory of Lexicography. Hock, Hans Heinrich (Hrsg.). 1997. Historical, Indoeuropean and Lexicographical Studies. A Festschrift for Ladislav Zgusta on the 
Occasion of his 70th Birthday: 319-380. Trends in Linguistics. Studies and Monographs 90. Berlin: Mouton de Gruyter.

Wiegand, Herbert Ernst. 1998. Wörterbuchforschung. Untersuchungen zur Wörterbuchbenutzung, zur Theorie, Geschichte, Kritik und Automatisierung der Lexikographie. 1. Teilbd. Mit 159 Abbildungen im Text. Berlin/New York: Walter de Gruyter.

Wiegand, Herbert Ernst. 1998a. Altes und Neues zur Makrostruktur in alphabetischen Printwörterbüchern. Wiegand, Herbert Ernst (Hrsg.). 1998. Wörterbücher in der Diskussion III. Vorträge aus dem Heidelberger Lexikographischen Kolloquium: 348-372. Lexicographica. Series Maior 84. Tübingen: Max Niemeyer Verlag. [Auch in Wiegand 2000: 1428-1453.]

Wiegand, Herbert Ernst. 1998b. Lexikographische Textverdichtung. Entwurf einer vollständigen Konzeption. Zettersten, Arne, Viggo Hjørnager Pedersen und Jens Erik Mogensen (Hrsg.). 1998. Symposium on Lexicography VIII. Proceedings of the Eighth International Symposium on Lexicography May 2-4, 1996, at the University of Copenhagen: 1-35. Lexicographica. Series Maior 90. Tübingen: Max Niemeyer Verlag. [Auch in Wiegand 2000: 1454-1489.]

Wiegand, Herbert Ernst. 1999. Immken, Antje und Werner Wolski (Hrsg.). Semantics and Lexicography. Selected Studies (1976-1996). Lexicographica. Series Maior 97. Tübingen: Max Niemeyer Verlag.

Wiegand, Herbert Ernst. 1999a. Artikel einsprachiger Lernerwörterbücher, Textgestaltwahrnehmung und Suchbereichsstrukturen. Plädoyer für übersichtliche Printwörterbücher im Zeitalter der Neuen Medien. Skibitzki, Bernd und Barbara Wotjak (Hrsg.). 1999. Linguistik und Deutsch als Fremdsprache: 259-281. Tübingen: Max Niemeyer Verlag.

Wiegand, Herbert Ernst. 2000. Kammerer, Matthias und Werner Wolski (Hrsg.). Kleine Schriften. Eine Auswahl aus den Jahren 1970 bis 1999 in zwei Bänden. Bd. 1: 1970-1988; Bd. 2: 1988-1999. Berlin/New York: Walter de Gruyter.

Wiegand, Herbert Ernst. 2000a. Über Suchbereiche, Suchzonen und ihre textuellen Strukturen in Printwörterbüchern. Ein Beitrag zur Theorie der Wörterbuchform. Wiegand, H.E. (Hrsg.). 2000. Wörterbücher in der Diskussion IV. Vorträge aus dem Heidelberger Lexikographischen Kolloquium: 233-301. Lexicographica. Series Maior 100. Tübingen: Max Niemeyer Verlag.

Wiegand, Herbert Ernst. 2000b. Über tabellarische Wörterverzeichnisse und deren Wörterbuchartikel. Ein Beitrag zur Theorie der Wörterbuchform. Lexicographica 16: 212-234.

Wiegand, Herbert Ernst. 2000c. Adressierung in der ein- und zweisprachigen Lexikographie. Eine einführende Übersicht über die Forschungs- und Problemlage. Lexikos 10: 32-74.

Wiegand, Herbert Ernst. 2000d. Wissen, Wissensrepräsentation und Printwörterbücher. Heid, Ulrich, Stefan Evert, Egbert Lehmann und Christian Rohrer (Hrsg.). 2000. Proceedings of the Ninth EURALEX International Congress. EURALEX 2000. Stuttgart, Germany, August 8-12, 2000: 15-38. Stuttgart: Institut für Maschinelle Sprachverarbeitung, Universität Stuttgart.

Wiegand, Herbert Ernst. 2001. Was eigentlich sind Wörterbuchfunktionen? Kritische Anmerkungen zur neueren und neuesten Wörterbuchforschung. Lexicographica 17: 217-248.

Wiegand, Herbert Ernst. 2001a. Sprachkontaktwörterbücher, Typen, Funktionen, Strukturen. Igla, Birgit, Pavel Petkov und Herbert Ernst Wiegand (Hrsg.). 2001. Theoretische und praktische Probleme der Lexikographie. 1. Internationales Kolloquium zur Wörterbuchforschung am Institut Germanicum der St. Kliment Ohridski-Universität, Sofia, 7. bis 8. Juli 2000: 115-224. Germanistische Linguistik 161-162. Hildesheim/Zürich/New York: Georg Olms Verlag.

Wiegand, Herbert Ernst. 2002. Zur Makrostruktur und zu den äußeren Zugriffsstrukturen im de Gruyter Wörterbuch Deutsch als Fremdsprache. Wiegand, Herbert Ernst (Hrsg.). 2002. Perspektiven der pädagogischen Lexikographie des Deutschen II. Untersuchungen anhand des de Gruyter 
Wörterbuchs Deutsch als Fremdsprache: 413-442. Lexicographica. Series Maior 110. Tübingen: Max Niemeyer Verlag.

Wiegand, Herbert Ernst. 2002a. Altes und Neues zur Mediostruktur in Printwörterbüchern. Lexicographica 18: 168-252.

Wiegand, Herbert Ernst. 2002b. Über textuelle Strukturen der Wörterbuchartikel und Artikelnischen im de Gruyter Wörterbuch Deutsch als Fremdsprache. Zugleich ein Beitrag zur Weiterentwicklung einer Theorie der Wörterbuchform. Wiegand, Herbert Ernst (Hrsg.). 2002. Perspektiven der pädagogischen Lexikographie des Deutschen II. Untersuchungen anhand des de Gruyter Wörterbuchs Deutsch als Fremdsprache: 497-595. Lexicographica. Series Maior 110. Tübingen: Max Niemeyer Verlag.

Wiegand, Herbert Ernst. 2002c. Adressierung in zweisprachigen Printwörterbüchern. Wiegand, Herbert Ernst (Hrsg.). 2002. Studien zur zweisprachigen Lexikographie mit Deutsch VIII: 111-175. Germanistische Linguistik 166. Hildesheim/Zürich/New York: Georg Olms Verlag.

Wiegand, Herbert Ernst. 2002d. Equivalence in Bilingual Lexicography: Criticism and Suggestions. Lexikos 12: 239-255.

Wiegand, Herbert Ernst. 2003. Überlegungen zur Typologie von Wörterbuchartikeln in Printwörterbüchern. Ein Beitrag zur Theorie der Wörterbuchform. Lexicographica 19: 169-313.

Wiegand, Herbert Ernst. 2003a. Wörterbuch zur Lexikographie und Wörterbuchforschung/Dictionary of Lexicography and Dictionary Research. Städtler, Thomas (Hrsg.). 2003. Wissenschaftliche Lexikographie im deutschsprachigen Raum. Im Auftrag der Heidelberg Akademie der Wissenschaften: 417-437. Heidelberg: Winter Verlag.

Wiegand, Herbert Ernst. 2004. Überlegungen zur Mediostruktur in Fachwörterbüchern. Auch am Beispiel des „Wörterbuchs zur Lexikographie und Wörterbuchforschung“. Brdar-Szabó, Rita und Elisabeth Knipf-Komlosi (Hrsg.). 2004. Lexikalische Semantik, Phraseologie und Lexikographie. Abgründe und Brücken. Festgabe für Regina Hessky: 339-365. Duisburger Arbeiten zur Sprach- und Kommunikationswissenschaft 57. Frankfurt a. M.: Peter Lang Verlag.

Wiegand, Herbert Ernst. 2005. Über die Datenakzessivität in Printwörterbüchern. Einblicke in neuere Entwicklungen einer Theorie der Wörterbuchform. Lexikos 15: 196-230.

Wiegand, Herbert Ernst. 2005a. Angaben, funktionale Angabezusätze, Angabetexte, Angabestrukturen, Strukturanzeiger, Kommentare und mehr. Ein Beitrag zur Theorie der Wörterbuchform. Lexicographica 21: 202-379.

Wiegand, Herbert Ernst. 2005b. Äquivalenz, Äquivalentdifferenzierung und Äquivalentpräsentation im zweisprachigen Wörterbüchern. Eine neue einheitliche Konzeption. Gottlieb, Henrik, Erik Jens Mogensen und Arne Zettersten (Hrsg.). Symposium on Lexicography XI. Proceedings of the Eleventh International Symposium on Lexicography May 2-4, 2002 at the University of Copenhagen: 17-57. Lexicographica. Series Maior 115. Tübingen: Max Niemeyer Verlag.

Wiegand, Herbert Ernst. 2005c. Über die textuellen Strukturen im GWDS. Wiegand, Herbert Ernst (Hrsg.). 2005. Untersuchungen zur kommerziellen Lexikographie der deutschen Gegenwartssprache II. Duden. Das große Wörterbuch der deutschen Sprache in zehn Bänden. Print- und CDROM-Version. 2. Bd.: 295-335. Lexicographica. Series Maior 121. Tübingen: Max Niemeyer Verlag.

Wiegand, Herbert Ernst. 2005d. Äquivalentpräsentation und Wörterbuchfunktionen in zweisprachigen Printwörterbüchern. Mit einem Seitenblick auf die so genannte „moderne lexikographische Funktionslehre“. Igla, Birgit, Pavel Petkov und Herbert Ernst Wiegand (Hrsg.). 2005. Kontrastive Lexikologie und zweisprachige Lexikographie. 2. Internationales Kolloquium zur Wörter- 
buchforschung. St. Kliment Ohridski-Universität Sofia, 18. bis 19. Oktober 2002: 1-38. Germanistische Linguistik 179. Hildesheim/Zürich/New York: Georg Olms Verlag.

Wiegand, Herbert Ernst. 2006. Das Lern- und Konsultationswörterbuch. Ein neuer Fachwörtertyp am Beispiel der Wörterbücher zur Sprach- und Kommunikationswissenschaft (WSK). Lexikos 16: 205-221.

Wiegand, Herbert Ernst. 2006a. Die „Wörterbücher zur Sprach- und Kommunikationswissenschaft" (WSK) und ihre Benutzungsmöglichkeiten im Fach Deutsch als Fremdsprache. Dimova, Ana, Vida Jesenšek und Pavel Petkov (Hrsg.). 2006. Zweisprachige Lexikographie und Deutsch als Fremdsprache. Drittes Internationales Kolloquium zur Lexikographie und Wörterbuchforschung. Konstantin Preslavski-Universität Schumen, 23.-24. Oktober 2004: 1-35. Germanistische Linguistik 184-185. Hildesheim/Zürich/New York: Georg Olms Verlag.

Wiegand, Herbert Ernst. 2006b. Adressierung in Printwörterbüchern. Präzisierungen und weiterführende Überlegungen. Lexikographica 22: 187-261.

Wiegand, Herbert Ernst. 2007. Über Zugriffspfade in Printwörterbüchern. Ein Beitrag zur Schnittstelle von Benutzungshandlungen und Wörterbuchform. Lexikos 17: 180-211.

Wiegand, Herbert Ernst. 2007a. Aspectos escogidos de una teoria de las estructuras textuales de los diccionarios. Souto, Mar Campos, Eugenia Conde Noguerol, José Ignacio Pérez Pascual und José Porto Dapena (Hrsg.). 2007. Reflexiones sobre el diccionario: 35-63. Coruña Anexos de „Revista de Lexicografia“ 6. Coruña: Universidade da Coruña, Servizo de Publicacións.

Wiegand, Herbert Ernst. 2007b. Il riferimento indirizzato nei dizionari bilingui a stampa. Studi Italiani di Linguistica Teorica e Applicata: 7-87.

Wiegand, Herbert Ernst. 2007c. Sull'accessibilità ai dati nei dizionari a stampa. Sei considerazioni sugli ultimi sviluppi di una teoria sulla forma del dizionario. Studi Italiani di Linguistica Teorica e Applicata: 89-136.

Wiegand, Herbert Ernst. 2007d. Neuere Aspekte einer Theorie und Typologie von Wörterbuchartikeln und ihre Praxisrelevanz. Gottlieb, Henrik und Jens Erik Mogensen (Hrsg.) 2007. Dictionary Visions, Research and Practice. Selected Papers from the 12th International Symposium on Lexicography, Copenhagen 2004: 183-200. Amsterdam/Philadelphia: John Benjamins.

Wiegand, Herbert Ernst. 2007e. Zur Adressierung in Printwörterbüchern. Präzisierungen und weiterführende Überlegungen. Lexikographica 22: 187-261.

Wiegand, Herbert Ernst. 2008. Zugriffsstrukturen in Printwörterbüchern. Ein zusammenfassender Beitrag zu einem zentralen Ausschnitt einer Theorie der Wörterbuchform. Lexicographica 24: 209-315.

Wiegand, Herbert Ernst. 2008a. Wörterbuchregister. Grundlagen einer Theorie der Register in modernen Printwörterbüchern. Lexikos 18: 256-302.

Wiegand, Herbert Ernst. 2009. Adressierung in der ein- und zweisprachigen Lexikographie. Eine zusammenfassende Darstellung. Kürschner, Wilfried und Manfred Ringmacher (Hrsg.). Aus Ost und West. Erträge des 3. und 4. Ost-West-Kolloquiums. [Erscheint].

Wiegand, Herbert Ernst. 2009a. Nichtnatürlich über natürliche Sprache schreiben. Zu einigen formalen Aspekten von Wörterbuchartikeln. Heidelberger Jahrbücher 53.2009: 247-285. 